\title{
DESIGN GUIDELINES FOR TURBO ROUNDABOUT BASED ON INTERSECTION SIGHT DISTANCE TO CIRCULATING CONFLICTING VEHICLE
}

\author{
By \\ AKSHAY SALWAN \\ Bachelor of Technology in Civil Engineering, PTU Punjab, India, 2016
}

\author{
A Project \\ presented to Ryerson University
}

\author{
in partial fulfilment of the \\ requirements of the degree of \\ Master of Engineering \\ in the program of \\ Civil Engineering
}

Toronto, Ontario, Canada, 2019

(C)Akshay Salwan, 2019 


\title{
Author's Declaration
}

I hereby declare that I am the sole author of this project. This is a true copy of the project, including any required final revisions, as accepted by my examiners.

I authorize Ryerson University to lend this project to other institutions or individuals for the purpose of scholarly research.

I further authorize Ryerson University to reproduce this project by photocopying or by other means, in total or in part, at the request of other institutions or individuals for the purpose of scholarly research.

I understand that my project may be made electronically available to the public.

\author{
Akshay Salwan \\ Department of Civil Engineering \\ Ryerson University.
}


DESIGN GUIDELINES FOR TURBO ROUNDABOUT BASED ON INTERSECTION SIGHT DISTANCE TO CIRCULATING CONFLICTING VEHICLE

Master of Engineering, 2019

By Akshay Salwan

Department of Civil Engineering

\begin{abstract}
Turbo Roundabout is a roundabout provided with spiral circulatory roadways for effectively counteracting the problems of modern multilane roundabout. This roundabout has an edge over modern roundabouts regarding capacity and safety and was first developed by Professor Fortujin in 1996.Turbo roundabouts are present in large percentage in Europe and is still in developing phase in North-America. Although in all the guidelines nothing has been mentioned about one important parameter of roundabout i.e. visibility. Visibility or Sight distance helps us to shape the geometry of intersection and aids in safety. In this paper sight distance analysis is going to be analysed on turbo roundabouts with a focus on Intersection Sight Distance to circulating conflicting vehicle. The traditional graphical approach has been supplemented with the analytical solution consisting of derivation of generalized mathematical equations for intersection sight distance for conflicting circulating vehicle at turbo roundabout.
\end{abstract}




\section{Table of Content}

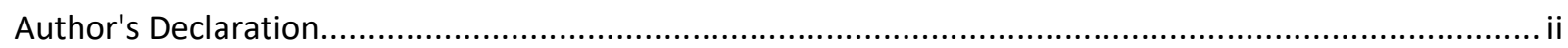

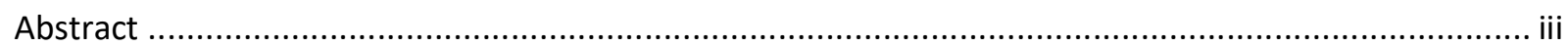

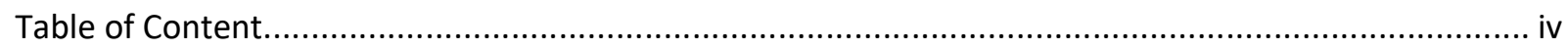

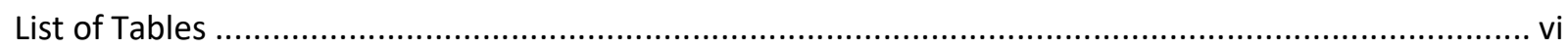

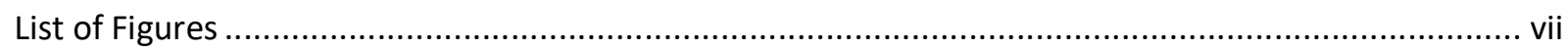

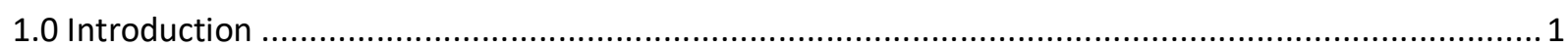

1.1 Problem with existing multi lane modern Roundabout.......................................................... 2

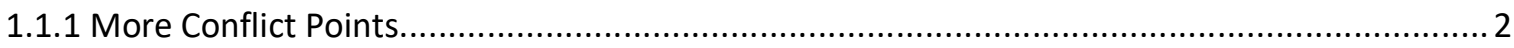

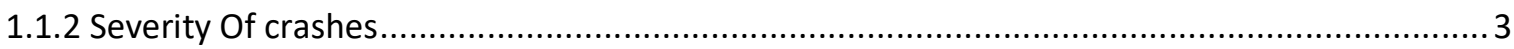

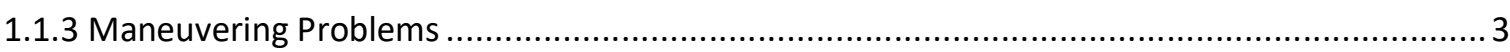

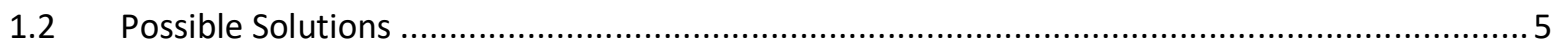

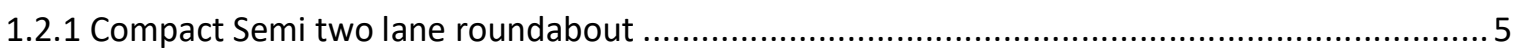

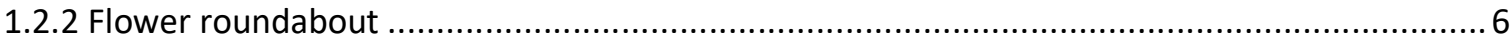

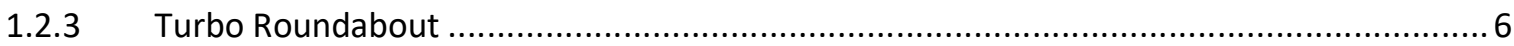

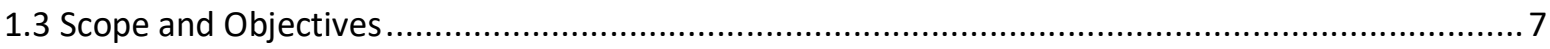

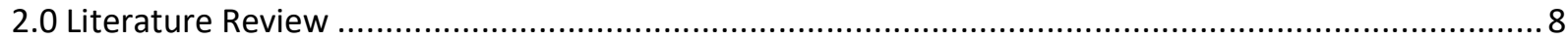

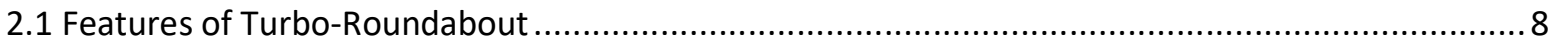

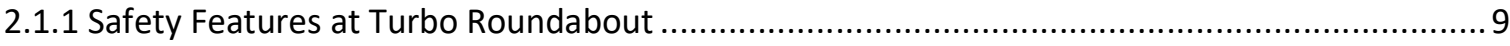

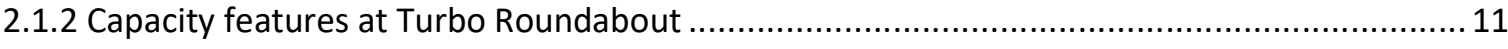

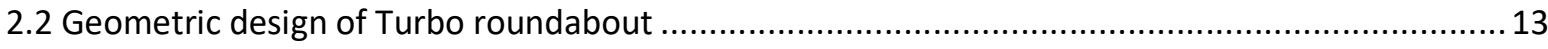

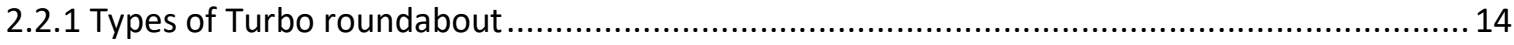

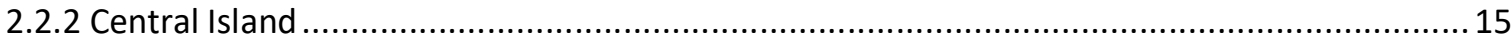

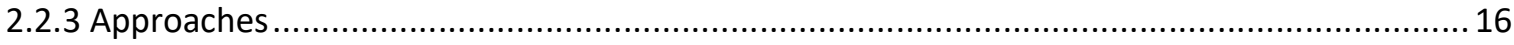

2.2.4 Design Vehicle

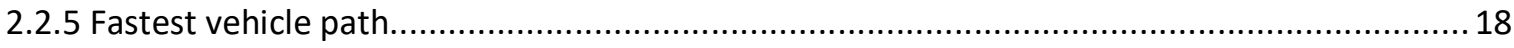

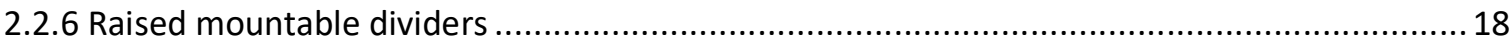

2.2.7 Additional geometric elements added on Turbo Roundabout...............................................2 20

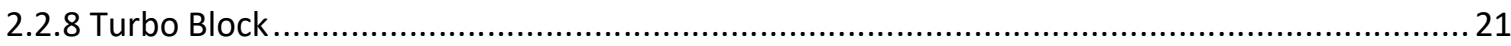


2.2.9 Movement of traffic flow in turbo roundabouts

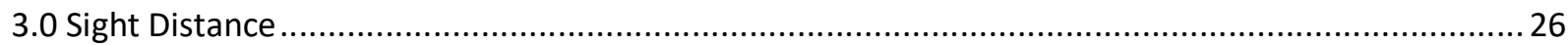

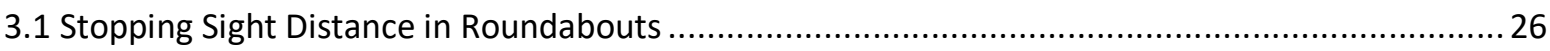

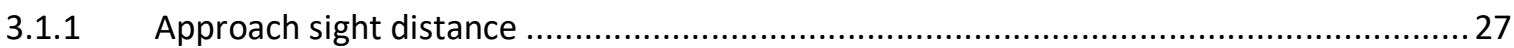

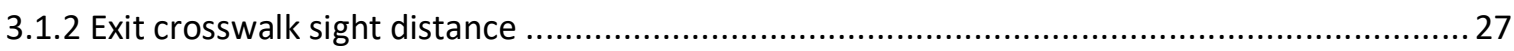

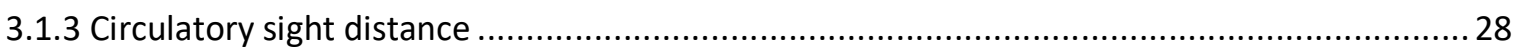

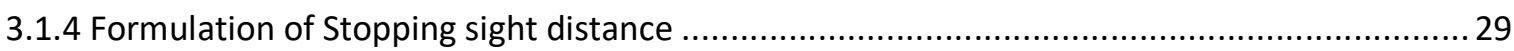

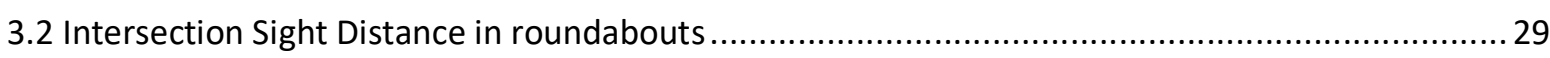

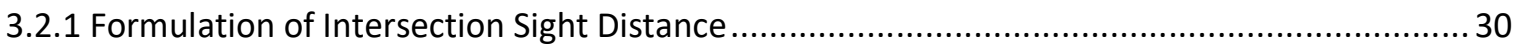

3.3 Intersection Sight Distance at Turbo Roundabouts (Graphical Representation) ............................33

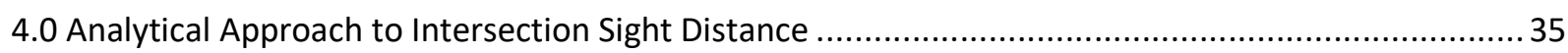

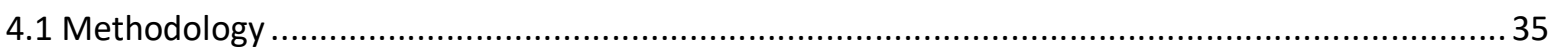

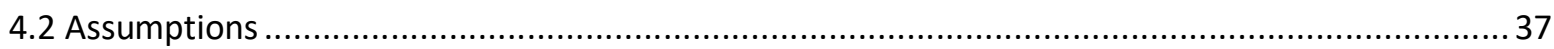

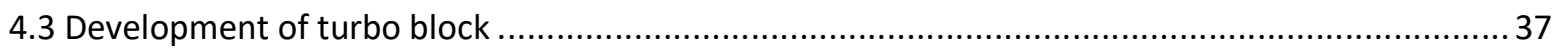

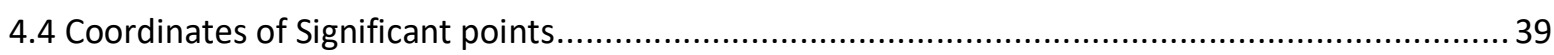

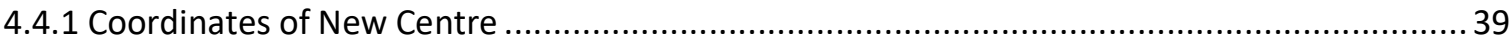

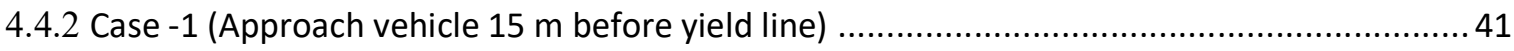

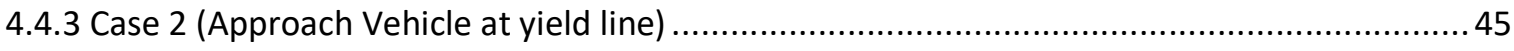

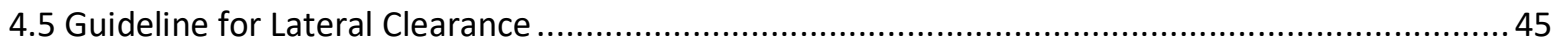

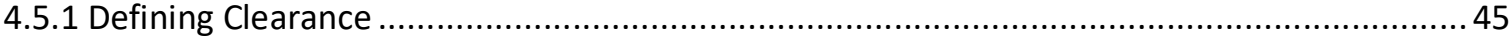

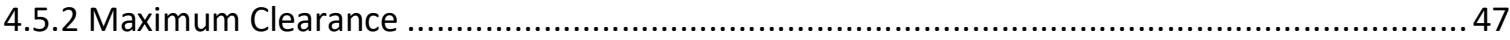

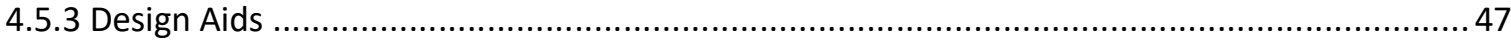

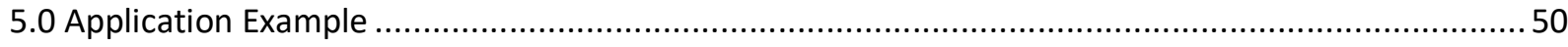

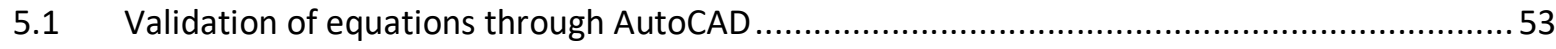

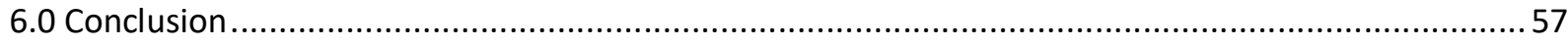

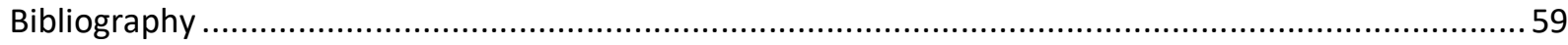




\section{List of Tables}

Table 1: Types of Roundabout and Location (Murphy \& Manager, 2015) ............................................ 10

Table 2: Crash rate at Roundabouts(Murphy \& Manager, 2015) ...................................................... 11

Table 3:Recommended parameter values of turbo-roundabout (Fortuijn, Lambertus G H. 2009)...........16

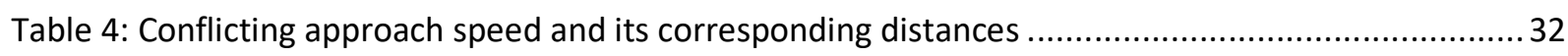

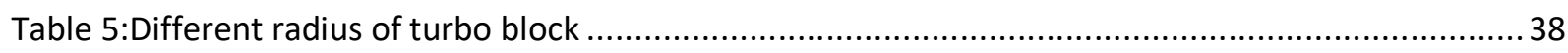

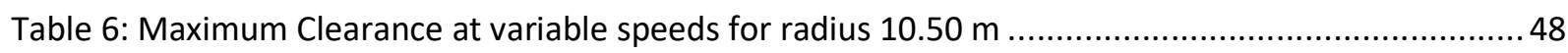

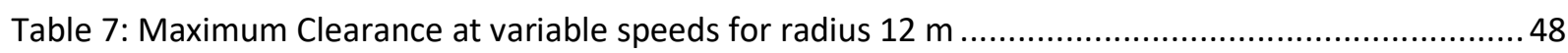

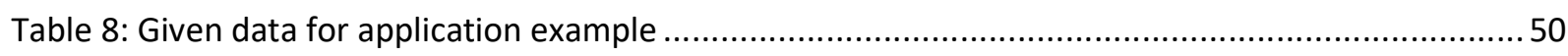

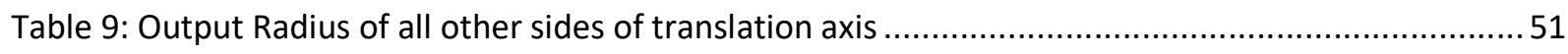

Table 10: Coordinates of significant points for vehicle at $15 \mathrm{~m}$ before yield line ..................................... 51

Table 11: Coordinates of significant values when vehicle is at yield line ..............................................52

Table 12:Comparison of results of analytical \& Graphical Approach...................................................5 


\section{List of Figures}

Figure 1:Conflict points in Intersection, single lane and double lane roundabout (Source: Walkability Audit Shows Promise for City. (2014, December 29)

Figure 2:Graphical comparison of crashes between single lane and multilane roundabout (TRB,

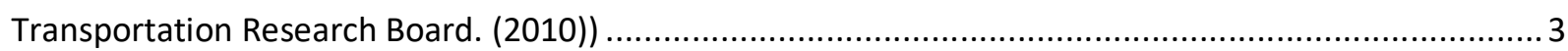

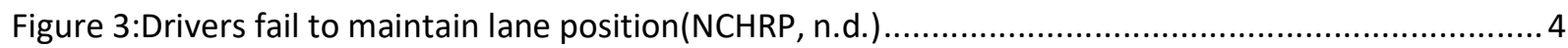

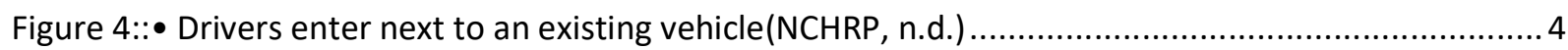

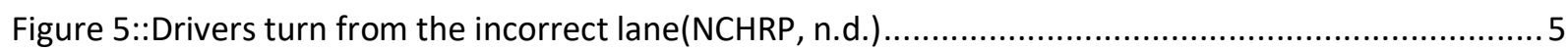

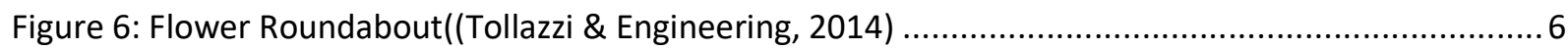

Figure 7: Layout of Turbo Roundabout(J.C. Engelsman and M. Uken, n.d.) ........................................ 8

Figure 8: Conflict points in double lane and turbo roundabout(Murphy \& Manager, 2015).....................9

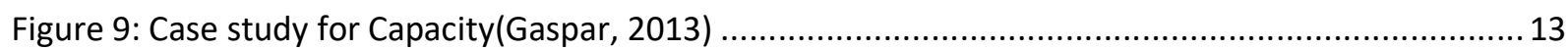

Figure 10: Turbo roundabout and its geometric features(Murphy \& Manager, 2015)............................14

Figure 11: Types of Turbo-Roundabouts(Džambas, Ahac, \& Dragčević, 2017) …................................. 15

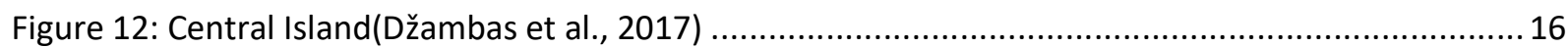

Figure 13: Raised Mountable dividers((Tollazzi \& Engineering, 2014) .................................................. 19

Figure 14: Traversable beginning on a mountable lane divider(Džambas et al., 2017) ........................... 19

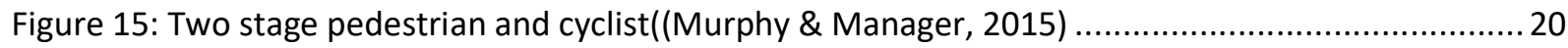

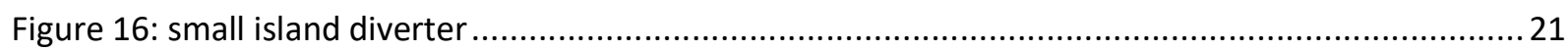

Figure 17: Turbo Block for Dutch, Croatian and Slovenia(Džambas et al., 2017) ..................................22

Figure 18:Cross section of Turbo Block Dutch, Croatian and Slovenia(Džambas et al., 2017) ................. 22

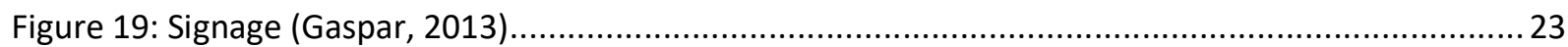

Figure 20: Swept path of the vehicles clockwise A-BUS at inner circulatory lane, WB-20D at inner circulatory lane, A-BUS at outer circulatory lane, WB-20D outer circulatory lane ...................................24

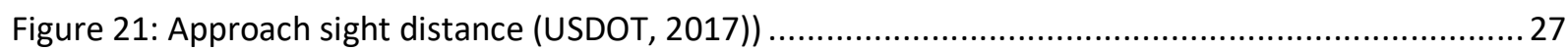

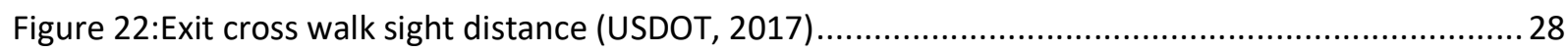

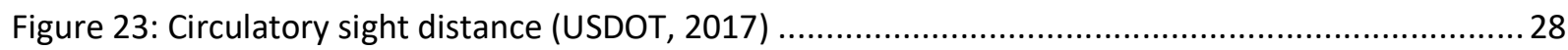

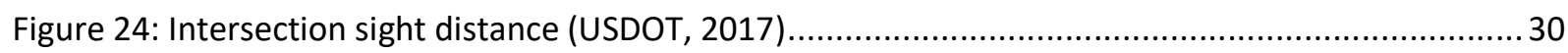

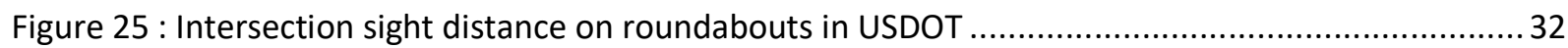

Figure 26: Sight Distances at all approaches. Approach 1, Approach 2, Approach 3, Approach 4

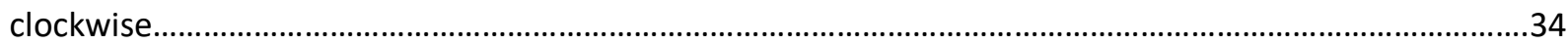

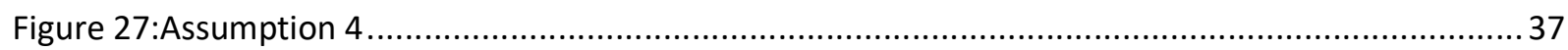

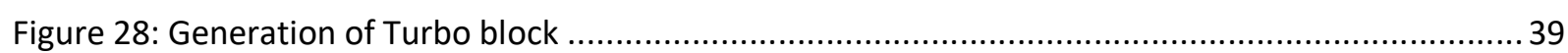

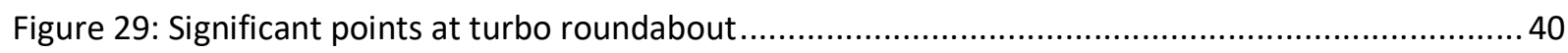

Figure 30:Graphical representation of clearance at different speeds for radius $10.50 \mathrm{~m} \ldots \ldots \ldots \ldots \ldots \ldots \ldots . . . . . . . . . .49$

Figure 31:Graphical representation of clearance at different speeds for radius $12 \mathrm{~m}$...........................49

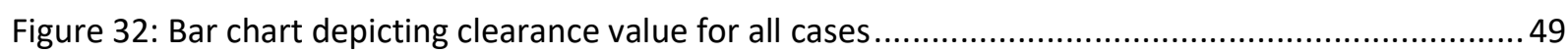

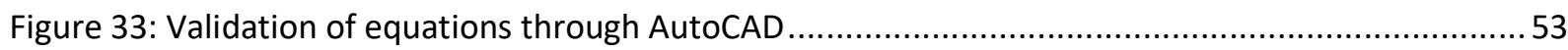




\subsection{Introduction}

Roundabout, although to a layman is mere a circular unsignalized intersection, is largely popular in Europe. Despite its popularity in Europe it had its origins in Washington D.C where first circular Intersection was developed in DuPont (Pumphrey, C. (2018, March 08) Rapid fruitful improvements in roundabout designs took place in Europe while North America was still struggling to cope up traffic congestions and delays by use of conventional large diameters rotaries and traffic circles. Public resistance became hindrance in switching over to these safer options but in the last two-decades North America has managed to learn from its mistakes and is now rapidly replacing the signalised intersections with small diameters roundabouts. Out of total 400 roundabouts built in Canada since 1990 around 100 roundabouts have popped up alone in Quebec (Bailey, S. (2016, October 13). Roundabouts are increasing because their provision has been identified as highly safety treatment compared to signalised intersection. They are believed to have brought advantage not only in safety, delay, emissions and fuel savings but also provide alternative to low volume or high-volume traffic as they do not require phasing plans. They also add a dimension of aesthetics, which is not there in case of signalised intersections. Most of the roundabouts constructed and working are single lane roundabouts which are managing the traffic operations perfectly but when the congestion on roundabouts increases we switch over to multilane roundabouts. The need of multilane modern roundabout arises when single lane roundabout is not able to handle the capacity of traffic volume the intersection offers. We know that single lane roundabouts have many advantages as compared to signalised intersection but when this single lane roundabout is converted into multi-lane roundabouts lot of safety and capacity issues erupts. We are going to discuss in detail not only the issues and problems but also the possible way-outs to mitigate them. The most optimum solution for multi-lanes intersection was found to be turbo roundabouts. We, in the study to follow, will not only analyse turbo roundabout but also develop mathematical equations based on sight distance parameters which will assist as handy tools during design. 


\subsection{Problem with existing multi lane modern Roundabout}

\subsubsection{More Conflict Points}

We know that Single-lane roundabouts reduced collision frequency. The collision frequency is a result of the lower number of conflict points found at roundabouts compared to traditional intersections. Roundabouts have 75 percent less conflict points than a regular intersection, illustrated in (Figure 1). The conflict points are of three types: queuing conflicts, merge and diverge conflicts and crossing conflicts (E. HAUER, January,1988.). Crossing conflicts, the most serious type of conflict, are completely eradicated at a roundabout. Reduction of severity of collisions is achieved through the elimination of crossing conflicts at roundabouts although low operating speed also mitigate the severity of collisions by providing drivers with greater reaction time for sudden manoeuvres (MDOT, November 2007). Roundabouts have only 8 conflict points as compared to the 32 conflict point in signalised intersection. But when this single lane roundabout is converted to multi-lane roundabout then the conflict point again increases to 16 which increase the risk of collision twice as compared to single roundabouts as shown in figure 1.

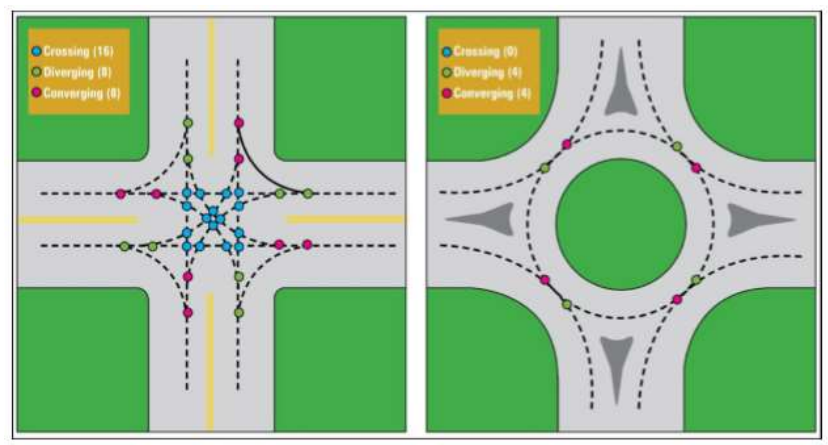

STANDARD MULTI-LANE

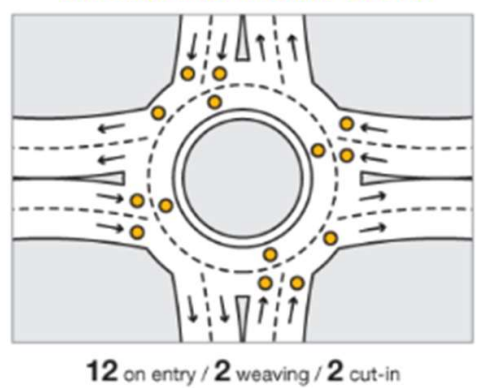

Figure 1:Conflict points in Intersection, single lane and double lane roundabout (Source: Walkability Audit Shows Promise for City. (2014, December 29) 


\subsubsection{Severity Of crashes}

The severity of the conflict points in single lane roundabout is far less than the severity of conflict points at Intersection as they are only merging and diverging conflicts. The reason behind it is that to decrease the exiting-circulating and entering-circulating crash rates we can increase the vehicle path curvature which is fine in single lane roundabout but when the same principle is applied in case of double lane roundabout, then the vehicle sideswipe collisions increases. Furthermore, the graph (fig-2) shows that the double lane roundabout has more crashes when compared to the single lane roundabout but still the interesting thing is that the injury collisions were same as in single lane roundabout. So the conclusion was the same as conducted by NYSDOT that multi-lane roundabouts are more prone to the PDO collisions i.e. property damage only(Weber \& Eng, 2007).

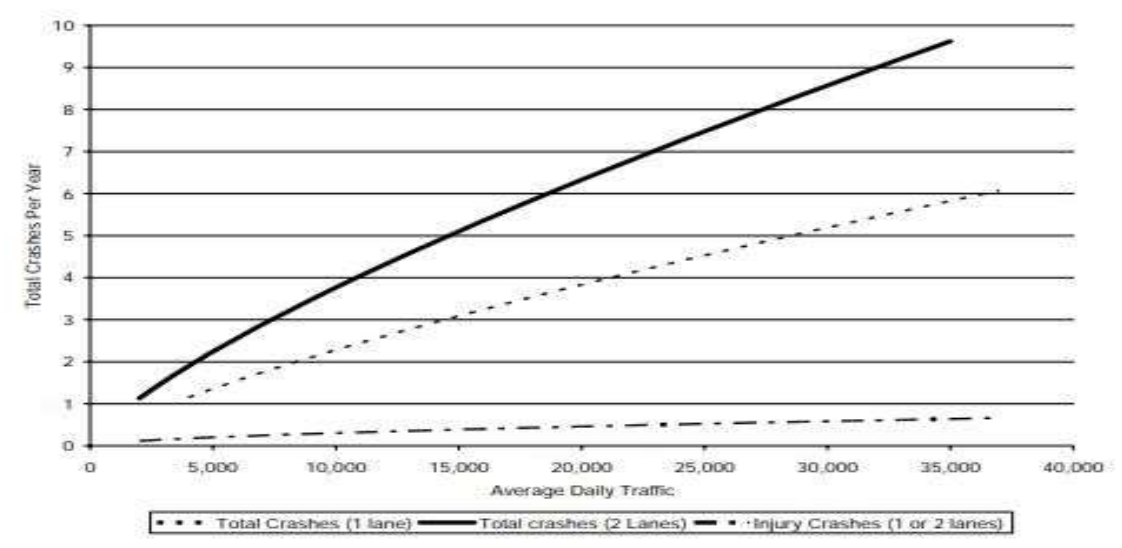

Figure 2:Graphical comparison of crashes between single lane and multilane roundabout (TRB, Transportation Research Board. (2010))

\subsubsection{Maneuvering Problems}

- Driver in left hand access lane has a drawback that it must change lanes over very short distance in roundabouts if he wants to exit. The situation is even worse if the roundabout has two exit lanes.

- Another principal problem is that the drivers behind the vehicle near the exit have no idea that whether the driver ahead will take an exit or will continue at roundabout.

- The final problem is reinforced by studies that show that there is very poor inner lane usage which ultimately leads to negative impact on capacity of roundabouts. 


\subsubsection{Driving behavior Problems}

While driving on multilane roundabouts drivers do some mistake because of the driving behaviour. The three main driving behaviour problems are-:

- Drivers fail to maintain lane position

- Drivers enter next to an exiting vehicle

- Drivers turn from the incorrect lane

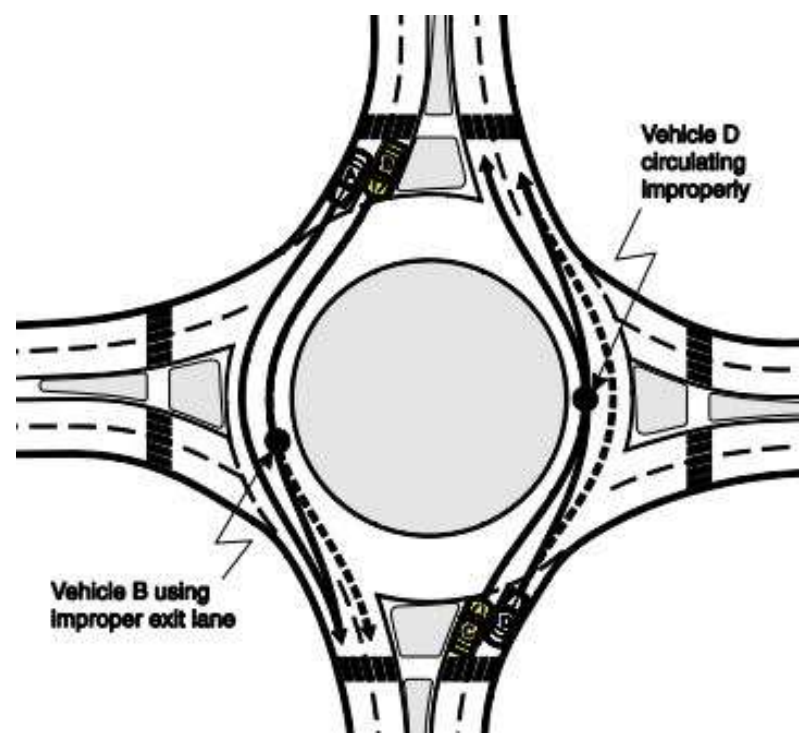

Figure 3:Drivers fail to maintain lane position(NCHRP, n.d.)

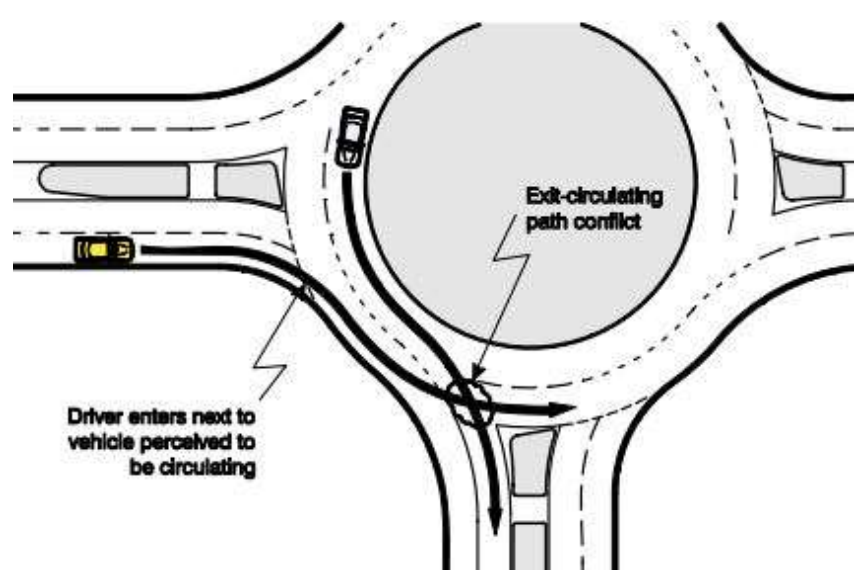

Figure 4::• Drivers enter next to an existing vehicle(NCHRP, n.d.) 


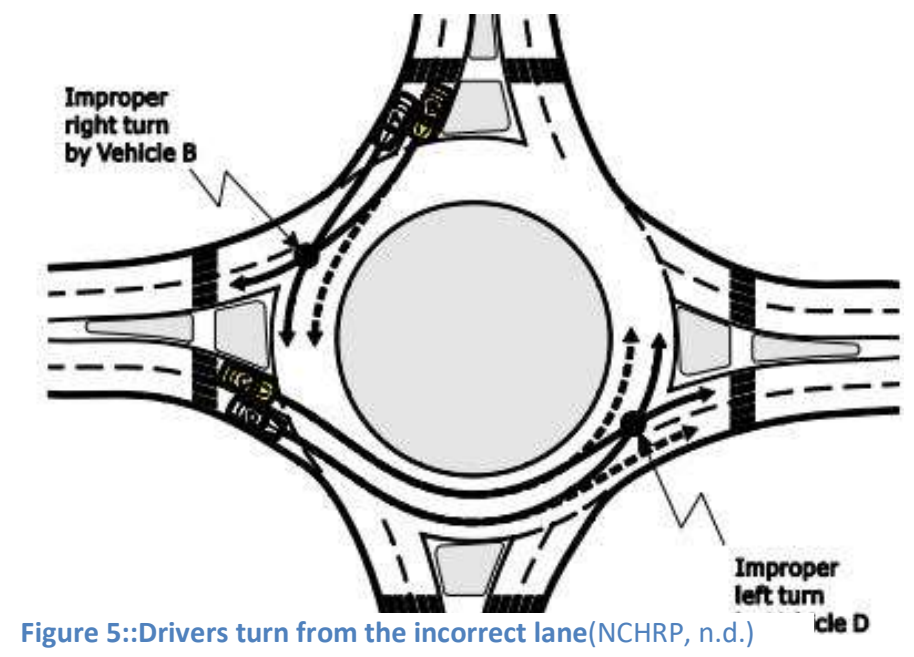

\subsection{Possible Solutions}

On deeply analysing the complications of multi-lane roundabout, the solution can be a type of roundabout that separates the inner circulatory traffic with the outer circulatory traffic. Designers have devised many solutions such as flower roundabout, compact-semi-two-lane roundabout, target roundabout and turbo roundabout. We will try to briefly explain the possible solutions in the succeeding subheadings.

\subsubsection{Compact Semi two lane roundabout}

This type of roundabout is already in use in Germany but has not been able to extend its roots to other European nations. The concept and design of single lane roundabout is like two-lane roundabouts; the only main difference is width of the circle lane. The circle lane is made wide enough so that passengers cars which are the major percentage of traffic volume can drive side by side and trucks and buses can use the whole width of the lane. This is very simple and effective solution but still not addresses all the problems mentioned above (Tomaž Tollazzi1, n.d.). 


\subsubsection{Flower roundabout}

To solve the above addressed problems, the only possible solution can be physically separating the lanes. Flower roundabout is one such an attempt which was developed in Slovenia. In flower roundabout right turning lanes are made depressed to achieve an efficient traffic operation and high road safety. The right turning driving vehicles have their own separated lane and the other lane becomes an inner circulatory carriageway. At reconstruction of existing two-lane roundabouts, we need not to change the position of outer road curbs, splitter islands and public lighting poles which influences the economics of the project (Tomaž Tollazzi1).

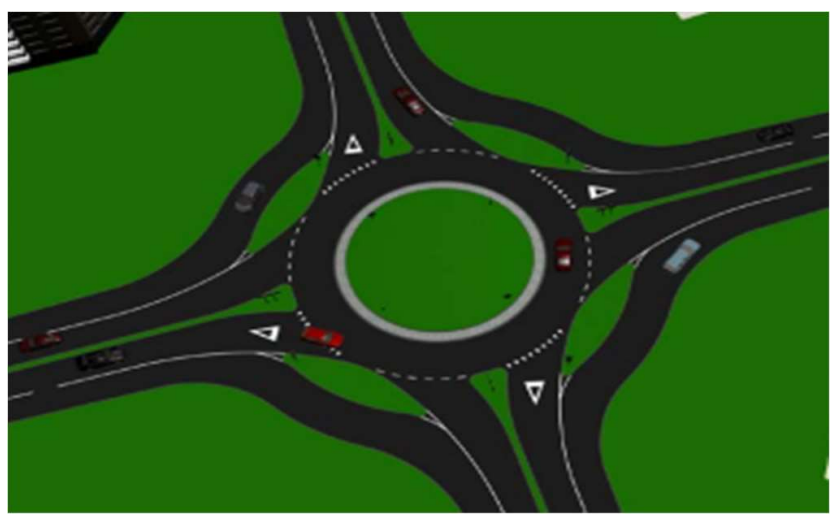

Figure 6: Flower Roundabout((Tollazzi \& Engineering, 2014)

\subsubsection{Turbo Roundabout}

A turbo-roundabout is a moderately new sort of roundabout, which gives a spiralling stream of traffic, expecting drivers to pick their course before entering the roundabouts. Professor L.G.H. Fortuijn first presented it the late 1990's as a more efficient and safer option in contrast to the standard multi-lane roundabouts. The first turbo-roundabout was worked in the Netherlands in 2000 and turned out to be popular to the point that the Dutch government built up its very own guidelines. There are about 300 turbo-roundabouts in the Netherlands and over 390 turboroundabouts all around the globe (Livingston, 2014).As in the case of other solutions turbo roundabouts also work on the same concept of separating the lane to avoid crashes. This emerged as better option as it also works with smaller radius of roundabouts. Turbo roundabout has now been adopted by some European as well as North American countries. 


\subsection{Scope and Objectives}

Turbo roundabouts are new type of roundabouts which are perceived to be more safe and efficient and are viable solution to the problems we face in modern multi-lane roundabouts. Quite a few papers have eulogized the benefits of this Dutch invention over conventional modern roundabouts. This paper will try to shed some light on visibility aspect of the turbo roundabout.

The main objective of this paper is formulating analytical equations for sight distance at turbo roundabouts which traditionally is performed graphically. The paper will develop general analytical models for lateral clearance at multi-lane turbo knee roundabout which will be based on intersection sight distance (ISD) for circulatory vehicle. The equations will be established for two cases; the first case (Case 1) will be when the approach vehicle is at $\mathrm{L}_{\min }(15 \mathrm{~m})$ before the yield line and the second case i.e. (Case 2) will be for the approach vehicle at yield line. The paper has already shed light on the problematic facts of multi-lane roundabouts and has briefly introduced the solutions to the existing problem. Furthermore, the paper will try to cover the geometric elements which shape the turbo roundabouts and will be discussed in detail in Chapter 2. Similarly, Chapter 3 explains sight distance on modern roundabouts and shows the graphical representation of sight distance on turbo roundabouts. The modelling part of the sight distances where a general sight distance and lateral clearance model is established using coordinate geometry and mathematical equations; true for all sizes of turbo knee roundabout, has been explained in chapter 4. We will end the paper by an application example in chapter 5 along with a validation section which is done through AutoCAD and will end with a conclusion in chapter 6. 


\subsection{Literature Review}

\subsection{Features of Turbo-Roundabout}

The main features that separate turbo-roundabouts from modern roundabouts are-:

- More than one entry lane.

- Raised dividers are inserted to discourage drivers from cutting in.

- Roundabouts will have two lanes one for continuing at roundabouts other for exiting at roundabout.

- Design of turbo roundabouts allows us to have smaller diameter roundabouts i.e. 50 meters.

- It eliminates the necessity of weaving due to the spiral lane marking.

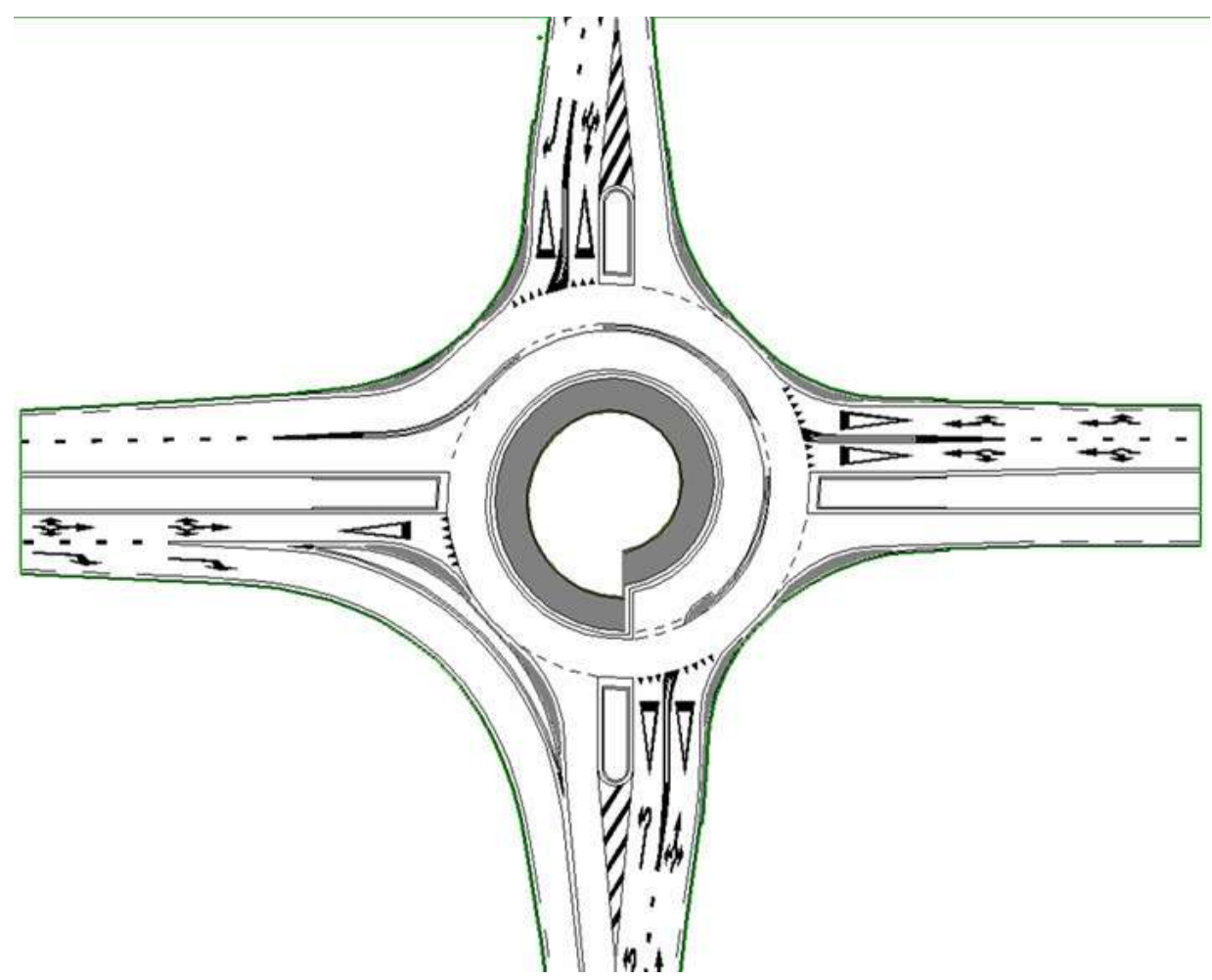

Figure 7: Layout of Turbo Roundabout(J.C. Engelsman and M. Uken, n.d.) 


\subsubsection{Safety Features at Turbo Roundabout}

The primary objective of developing turbo roundabout was to enhance the safety at multi-lane roundabouts. The above mentioned geometric attributes give vehicle the ability to yield to only one lane instead of two lanes while entering turbo-roundabout. It is one of the biggest advantages of turbo roundabout that number of conflict points is reduced in it. The main safety features provided by the turbo roundabouts were-:

- The conflict points in multilane roundabouts were found to be 16 in case of single exit and 20 in case of two-lane exit. Turbo roundabout reduced this to just 10 conflict points (Murphy \& Manager, 2015) .

- Other than that, the turbo roundabout forces drivers to have lower vehicle speeds due to narrow paths which advocate it as a safer option.

- Traffic inside the circulatory roadway has the choice of either exiting the roundabout or continue it; this does not allow weaving which ultimately reduces the conflict points.

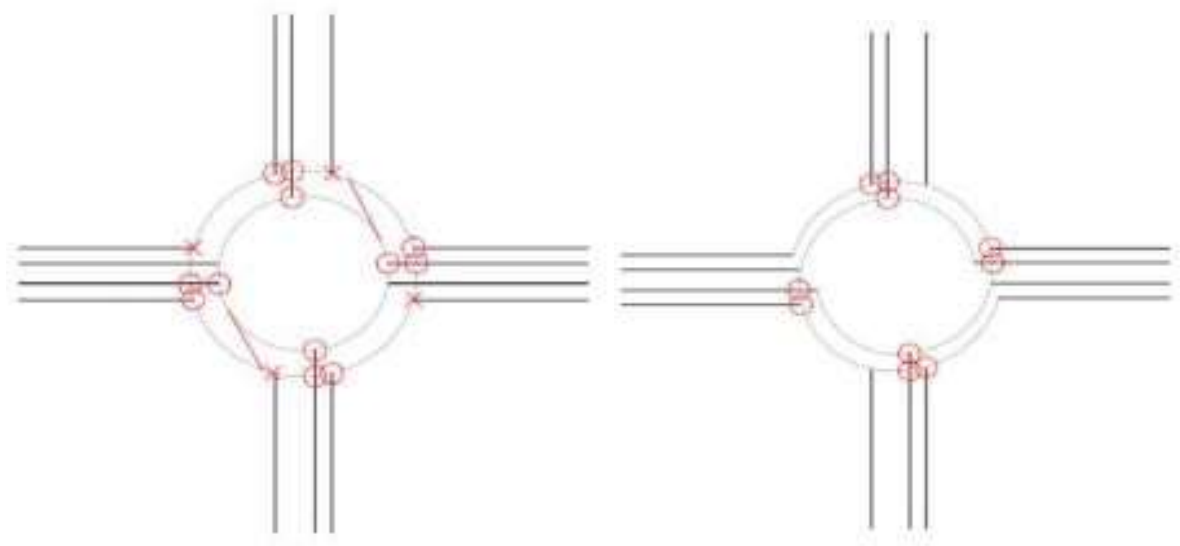

Figure 8: Conflict points in double lane and turbo roundabout(Murphy \& Manager, 2015)

- This solves the principal manoeuvre problem mentioned in article 1.1 which ultimately leads to crashes. Here the problem is solved as once the driver enter the lane chosen he has a better anticipation of the movement of the vehicle in front of him, as the number of exits for both inner and outer circulatory roadway are reduced to two and that also very gradual exits in contrast to multi-lane roundabout.

- A driver behaviour problem to maintain lane position and turning to an incorrect lane which causes accidents is also solved due to the separation of lanes. 
A case study was done (Murphy \& Manager, 2015) where they analysed crash rates of different multi-lane roundabouts which included spiral lane roundabout, two-lane roundabout and Turbo roundabout. The location and type of roundabout on which they carried out case study has been compiled into Table 1. The source of collision data was ICBC collision data website between year 2011-2013.

Altogether there were 711 records for the multi-lane roundabouts in B.C. between 2011-2013. Table 2 bridges the recurrence of crashes by year by area. By and large, there have been around 21 crashes for every year at multi-lane roundabouts in B.C. The range was from as high as 44

Table 1: Types of Roundabout and Location (Murphy \& Manager, 2015)

\begin{tabular}{|l|c|l|}
\hline \multicolumn{1}{|c|}{ Location } & Jurisdiction & \multicolumn{1}{|c|}{ Description } \\
\hline Marshall Road \& Clearbrook Road & Abbotsford & $\begin{array}{l}\text { Spiral roundabout ( 3 - 2 lane exits, 2 right } \\
\text { turn bypass lanes) }\end{array}$ \\
\hline Evans Road \& Yale Road & Chilliwack & $\begin{array}{l}2 \text { lane roundabout ( 4 - 2 lane entries, } 4 \text { - 2 } \\
\text { lanes exists) }\end{array}$ \\
\hline McCallum Road \& Highway 1 Interchange & Abbotsford & $\begin{array}{l}2 \text { Spiral roundabouts (both with 3 - 2 lane } \\
\text { exits) }\end{array}$ \\
\hline 8th Avenue \& Highway 99 & Surrey & $\begin{array}{l}2 \text { lane roundabout ( 2 - 2 lane entries, 2 - 2 } \\
\text { lane exits) }\end{array}$ \\
\hline Mount Lehman Road \& South Fraser Way & Abbotsford & $\begin{array}{l}2 \text { lane roundabout (3 legs, 2 - 2 lane entries, } \\
2 \text { - 2 lane exits) }\end{array}$ \\
\hline McTavish Interchange & Sydney & $\begin{array}{l}2 \text { Spiral roundabouts (2 lane entries, } 2 \text { lane } \\
\text { exits) }\end{array}$ \\
\hline 16th Avenue \& Westbrook Mall & UBC & $\begin{array}{l}\text { Spiral roundabout ( 1 lane exits, 2 right turn } \\
\text { bypass lanes) }\end{array}$ \\
\hline Commercial Way \& Discovery Way & Squamish & $\begin{array}{l}2 \text { lane roundabout (2 lane entries, } 2 \text { lane } \\
\text { exits) }\end{array}$ \\
\hline Willingdon Road \& Electra Boulevard & Victoria Airport & $\begin{array}{l}\text { Turbo roundabout (knee, } 3 \text { legs, } 1 \text { - 2 lane } \\
\text { entry, 1 - 2 lane exit) }\end{array}$ \\
\hline
\end{tabular}

crashes for every year at the Marshall Road and Clearbrook Road, to as low as 0.3 impacts every year at the Turbo roundabout. As far as accident recurrence, we observed that the Turbo Roundabout encountered a greatly improved road safety than any other multi-lane roundabouts. The case study further legitimatise itself by normalizing crash frequency in a way that at an intersection where there is more traffic, by logic there will be more crash frequency. To normalise, the volume of traffic at each intersection was approximated at high traffic flow for crash rate 
analysis. The conclusion of the study based on data of Table- 2 was very much clear that the turbo roundabout gives us far more road safety performance as compared to other multi-lane roundabouts.

Table 2: Crash rate at Roundabouts(Murphy \& Manager, 2015)

\begin{tabular}{|c|c|c|c|c|c|c|c|c|}
\hline \multirow[b]{2}{*}{ Location } & \multicolumn{3}{|c|}{ Crashes } & \multirow{2}{*}{$\begin{array}{l}\text { Total } \\
\text { Crashes }\end{array}$} & \multirow{2}{*}{$\begin{array}{c}\text { Crashes / } \\
\text { Year / } \\
\text { Roundabout }\end{array}$} & \multicolumn{2}{|c|}{ Estimated Traffic } & \multirow{2}{*}{$\begin{array}{c}\text { Crash } \\
\text { Rate } \\
\text { (/MEV) }\end{array}$} \\
\hline & 2011 & 2012 & 2013 & & & AWDT & $\begin{array}{l}\text { Yearly } \\
\text { Traffic }\end{array}$ & \\
\hline $\begin{array}{l}\text { Marshall Road \& } \\
\text { Clearbrook Road }\end{array}$ & 38 & 47 & 48 & 133 & 44.3 & 25000 & 8750000 & 5.07 \\
\hline $\begin{array}{l}\text { Evans Road \& Yale } \\
\text { Road }\end{array}$ & 33 & 35 & 37 & 105 & 35.0 & 24000 & 8400000 & 4.17 \\
\hline $\begin{array}{l}\text { McCallum Road \& } \\
\text { Highway } 1 \text { Interchange }\end{array}$ & 95 & 50 & 45 & 190 & 31.7 & 28000 & 9800000 & 3.23 \\
\hline $\begin{array}{l}\text { 8th Avenue \& Highway } \\
99\end{array}$ & 26 & 19 & 38 & 83 & 27.7 & 18000 & 6300000 & 4.39 \\
\hline $\begin{array}{l}\text { Mount Lehman Road \& } \\
\text { South Fraser Way }\end{array}$ & 17 & 16 & 25 & 58 & 19.3 & 30000 & 10500000 & 1.84 \\
\hline McTavish Interchange & 41 & 34 & 33 & 108 & 18.0 & 26000 & 9100000 & 1.98 \\
\hline $\begin{array}{l}\text { 16th Avenue \& } \\
\text { Westbrook Mall }\end{array}$ & 16 & 8 & 3 & 27 & 9.0 & 15000 & 5250000 & 1.71 \\
\hline $\begin{array}{l}\text { Commercial Way \& } \\
\text { Discovery Way }\end{array}$ & 0 & 4 & 2 & 6 & 2.0 & 1000 & 350000 & 5.71 \\
\hline $\begin{array}{l}\text { Willingdon Road \& } \\
\text { Electra Boulevard }\end{array}$ & 0 & 0 & 1 & 1 & 0.3 & 4300 & 1505000 & 0.22 \\
\hline
\end{tabular}

\subsubsection{Capacity features at Turbo Roundabout}

As stated earlier that turbo roundabout main feature is its safety feature but apart from it; it has been found as better at capacity aspect also when compared to double-lane roundabout. When talking about capacity a study by (Fortuijn 2009) gives the capacity formula for calculating the capacity of turbo-roundabout. Despite the detailed capacity analysis by (Fortuijn 2009) nothing significant was mentioned for heavy traffic flow. (Giuffre, Grana ,2016) tried to measure the effect of heavy vehicle flow on turbo roundabout using microsimulation tool. They tried to observe the effect on capacity at different percentages of truck vehicle in total fleet of vehicles. For which they used the concept of (PCE) i.e. Passenger Car Equivalent. The passenger car equivalent is unit used to assess the traffic-flow rate. According to (AASTHO) PCE uses private passenger car as 1 unit 
and motorcycle as 0.5 unit. Our interest in this study is at heavy vehicles i.e. bus, tractor or truck for which they estimate PCE value at different percentage of heavy vehicles. (Giuffre, Grana ,2016) uses a proper methodology where after laying out the turbo roundabout geometric features using the swept path of the vehicle the circulating flow is reproduced using origin-destination matrices and capacity is analysed for two cases. The first one is for $\mathrm{C}_{\mathrm{car}}$ i.e. the capacity in case of traffic demand of passenger cars only, the second case would be $C_{P}$ i.e. the capacity in case of traffic demand corresponding to "P" percentage of heavy vehicles. The results then are injected in the following equation for which $\mathrm{E}_{\mathrm{T}}$ i.e. PCE for different percentage of heavy traffic flow is estimated.

$\mathrm{C}_{\mathrm{car}}=(1-\mathrm{P}) * \mathrm{C}_{\mathrm{P}}+\mathrm{P} * \mathrm{C}_{\mathrm{P}} * \mathrm{E}_{\mathrm{T}}$

Where $\mathrm{C}_{\text {car }}$ is the capacity in case of traffic demand of passenger cars only.

$\mathrm{C}_{\mathrm{P}}$ is the capacity in case of traffic demand corresponding to "P" percentage of vehicles.

$\mathrm{E}_{\mathrm{T}}$ is the passenger car equivalent factor.

The results of the (Giuffre, Grana ,2016) were done for two cases; the first one for right-lane on major entries and left-lane for major entries. The results showed that a PCE of less than 2 should be used for major entries at usual heavy traffic flow i.e. $10 \%$ to $20 \%$ and at minor entries the PCE value of 4.5 can be reached for $10 \%$ to $20 \%$ heavy traffic flow. In contrary HCM suggests a value of $\mathrm{E}_{\mathrm{t}}=2$ for both the major and minor entries; so, it is overestimating effect of heavy traffic flow at major entries and underestimating at minor entries. For higher percentage of heavy vehicle traffic we can use similar methodolgy to estimate PCE value for particular perecentage of heavy vehicles. So turbo roundabouts are effective in case of heavy vehicle flow as long as capacity of the intersection is analysed using the right passanger equivalent factor. According to the study conducted by (Giuffrè, Granà, \& Marino, 2012)turbo roundabouts perform better in terms of capacity than double lane roundabout. It was observed that fewer delays are experienced by the drivers when at turbo roundabout there is high traffic volume coming from major road and lowto-medium traffic flow comes from minor roads. Another observation was that when low-tomedium traffic enters from major roads both the roundabouts i.e. turbo and double lane roundabouts perform in equivalent way in terms of capacity. Recent studies also show that capacity of turbo roundabout is found to be $25 \%$ to $35 \%$ more than two-lane modern roundabout. (Fortuijn 2009) also provides us with the formula which gives the traffic proportion used by outer and inner lane. The study also revealed one situation when two-lane roundabout has more capacity i.e. when 
the proportion of right turn in minor direction is more than 60\%. (Gaspar, 2013) gave three particular situations in which turbo roundabout can have improvement in terms of capacity as compared to conventional roundabout. The three situations are-:

- When there is an increase in the number of right turns on the secondary lane.

- When there is an increase in the go-ahead movement in the dominant flow.

- When there is an equilibrated traffic distribution in all arms and directions of the turboroundabout.

To further prove their point (Gaspar, 2013) did a case study on Baden-Powell square in Lisbon, Portugal. The result of their case study is shown in graphical form in fig (9). The graph clearly shows the entry capacity is decreased during North-South entry approach and degree of
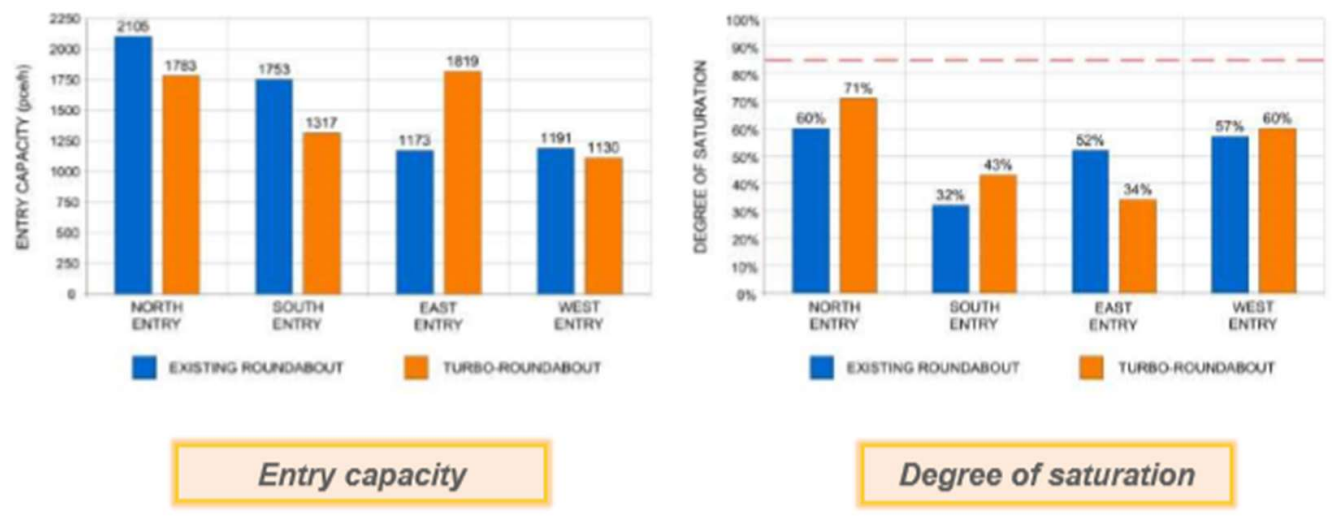

Figure 9: Case study for Capacity(Gaspar, 2013)

saturation is increased by more than $10 \%$ whilst there was a significant improvement of capacity in east entry with west entry remained approximately the same.

\subsection{Geometric design of Turbo roundabout}

Before digging deep into the sight distance of turbo roundabouts, the geometric design of turbo roundabout needs to be understood. As in the case of modern roundabout there are certain geometric features related to turbo roundabout such as Central Island, approaches etc. But first we need to study about different variations of turbo roundabout.(Gaspar, 2013). 


\subsubsection{Types of Turbo roundabout}

There are different variations of turbo roundabouts. Depending on whether it is four legged or three legged the different type of turbo roundabout is chosen.

- For four-legged intersection-: egg shape, knee shape and rotor

- For three leg intersection-: star shape, stretched-knee

For four-legged intersection Rotor or Star roundabouts are used when equal flow of traffic is there from all directions and egg shape is used when there is an unbalanced flow or predominant flow from one direction (Džambas, Ahac, and Dragčević 2008). In case where there is an

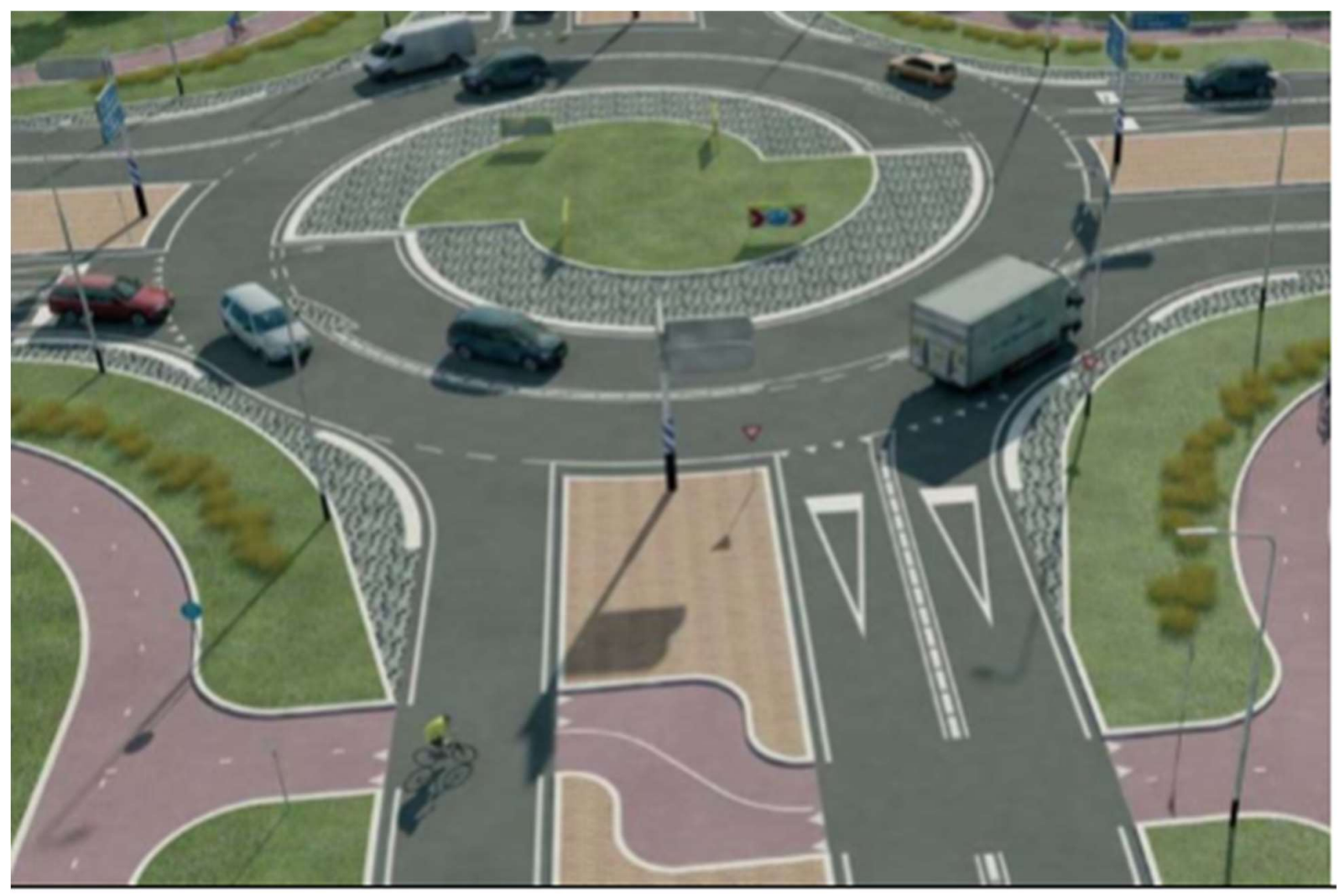

Figure 10: Turbo roundabout and its geometric features(Murphy \& Manager, 2015)

select an ovular roundabout which keeps the number of lanes on access road like the previous one and we don't need to extend the pavement area (Silva, Vasconcelos, and Santos 2014). 


\subsubsection{Central Island}

There are two parts of Central Island in turbo roundabouts

- Traversable i.e. mountable

- Non-Traversable i.e. non-mountable

As in case of modern roundabout the truck apron is used for vehicles with larger swept path (USDOT, 2017). Although Croatian, Serbian and Slovenian guideline suggest that the truck. apron should be used as a surface where emergency vehicles or regular vehicles in case of

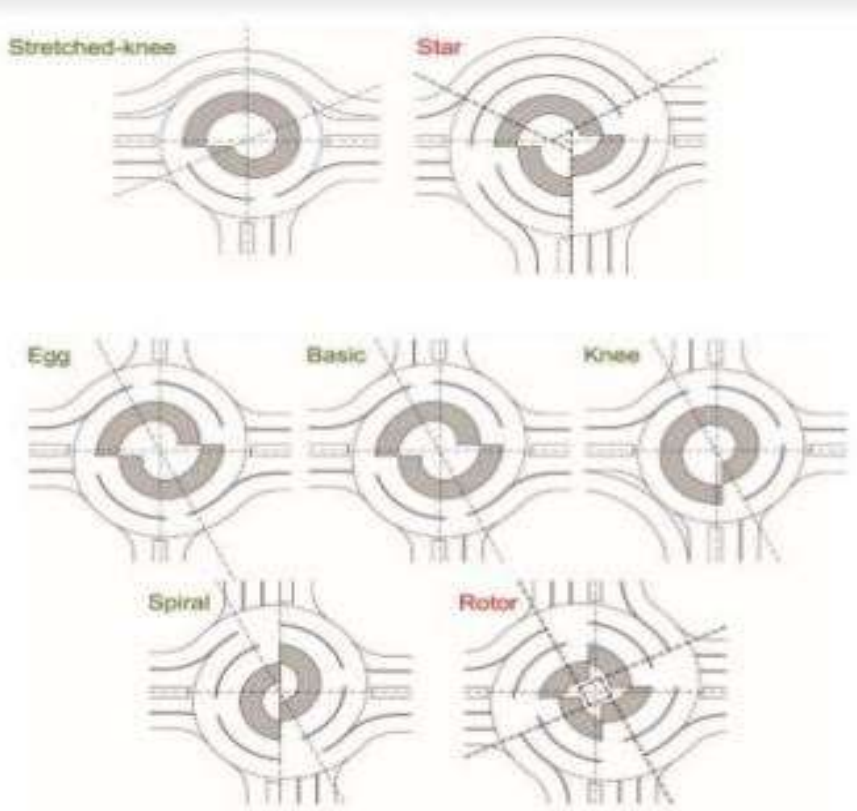

Figure 11: Types of Turbo-Roundabouts(Džambas, Ahac, \& Dragčević, 2017)

emergency can stop. The traversable apron can be of width $5 \mathrm{~m}$ which will help to accommodate vehicles larger than $22 \mathrm{~m}$ through roundabout. The non-traversable part can be used for placing traffic signs as they have a great place in efficient functioning of turbo-roundabouts. The beginning of traversable apron can be spiral, or flat but Dutch guidelines recommend flat beginning.(Džambas et al., 2017). 


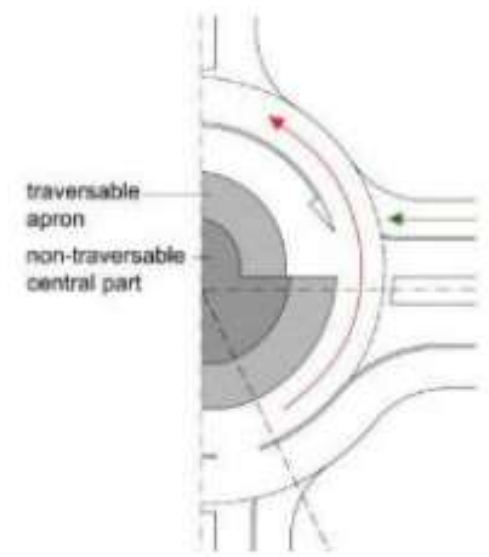

Figure 12: Central Island(Džambas et al., 2017)

\subsubsection{Approaches}

Turbo roundabouts are recommended to have approaches aligned at 90 degrees so that they can ease the ride ability of long vehicles. But often it becomes difficult to follow this guideline especially in case of reconstruction. The Dutch guideline does not give further solution to this problem. The following table shows the value of defining parameters of turbo-roundabout (Džambas, Ahac, and Dragčević 2008). It should be further noted that design of turbo roundabout approaches should be such that it does not exceed the maximum recommended value. Serbian and Slovenian guidelines do not recommend width of entry and exit lane. Recommendation for different parameter value feature of approaches is compiled in below

Table 3:Recommended parameter values of turbo-roundabout (Fortuijn, Lambertus G H. 2009)

\begin{tabular}{|l|ll|}
\hline \multicolumn{1}{|c|}{ Parameter } & \multicolumn{2}{c|}{ Recommended value } \\
\hline Width of single lane entry lane and exit lane & Entry: $4.0 \mathrm{~m}$ & Exit:4.5m \\
\hline Width of two lane entry lane and exit lane & Entry: $3.5 \mathrm{~m}$ & Exit: $4.0 \mathrm{~m}$ \\
\hline Width of splitter Island & Dutch guideline: 2.5 & Serbian guideline:2.0m \\
\hline Radius of entry and exit curve & Entry: $12 \mathrm{~m}$ & Exit:15m \\
\hline
\end{tabular}

\subsubsection{Design Vehicle}

It has been already discussed in the earlier section that the swept path of vehicle is determining factor in design of roundabout geometry. From the Dutch experience and their popular fleet of 
vehicles two axle truck with a three-axle semi-trailer is used as design vehicle. Different European guidelines have specified different vehicle dimensions which should be used as design vehicle. The following table shows the vehicle dimensions for Netherlands only as they have more experience of Turbo-roundabouts (Fortuijn, Lambertus G H. 2009).

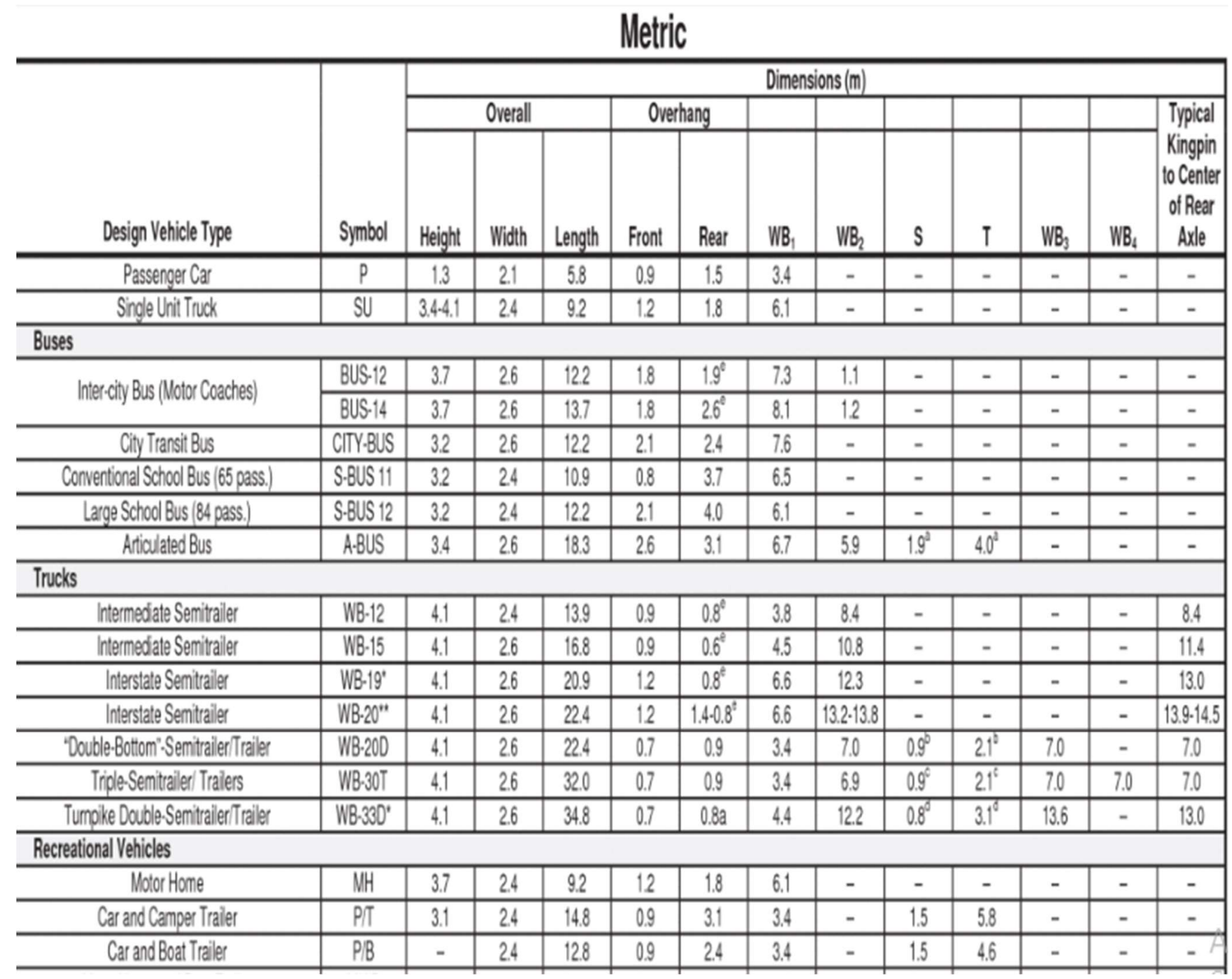




\subsubsection{Fastest vehicle path}

Modern roundabouts have four critical fastest route paths and turbo roundabouts have three critical fastest route paths which helps us to analyse roundabout in perfect manner. The three critical routes are-:

- Through movement

- Right turn from outer entry lane

- Right turn from inner entry lane

All the European guidelines agree to these three paths as critical paths. However Dutch guidelines recommend the distance of $1 \mathrm{~m}$ from the point of impact which is not safe as it does not guarantee unhindered passage of vehicle whereas when we provide minimum clearance of $2 \mathrm{~m}$ will result in greater curvature of vehicle path. Study by (Džambas, Ahac, and Dragčević 2008) shows that optimum minimum clearance is $1.5 \mathrm{~m}$. Although "Torus" software strictly followed Dutch guidelines the fastest vehicle paths on it gives no results even while analysing.

\subsubsection{Raised mountable dividers}

According to study by (Tollazi,, Renčelj,) there are some countries which dismisses the idea of mountable dividers and there are some which are in support of them. The people in support of these mountable dividers advocate the fact that without raised dividers drivers tend to change from inner lane to outer lane which causes safety issues. Although theoretically mountable dividers do not have great influence over capacity and safety these dividers require winter service and regular maintenance and is also a threat for two-wheeler safety (Livingston, 2014). Dutch guidelines recommended the use of these dividers and states that the width, height and length of these dividers should be $30 \mathrm{~cm}, 7 \mathrm{~cm}$ and $4 \mathrm{~m}$ respectively. 


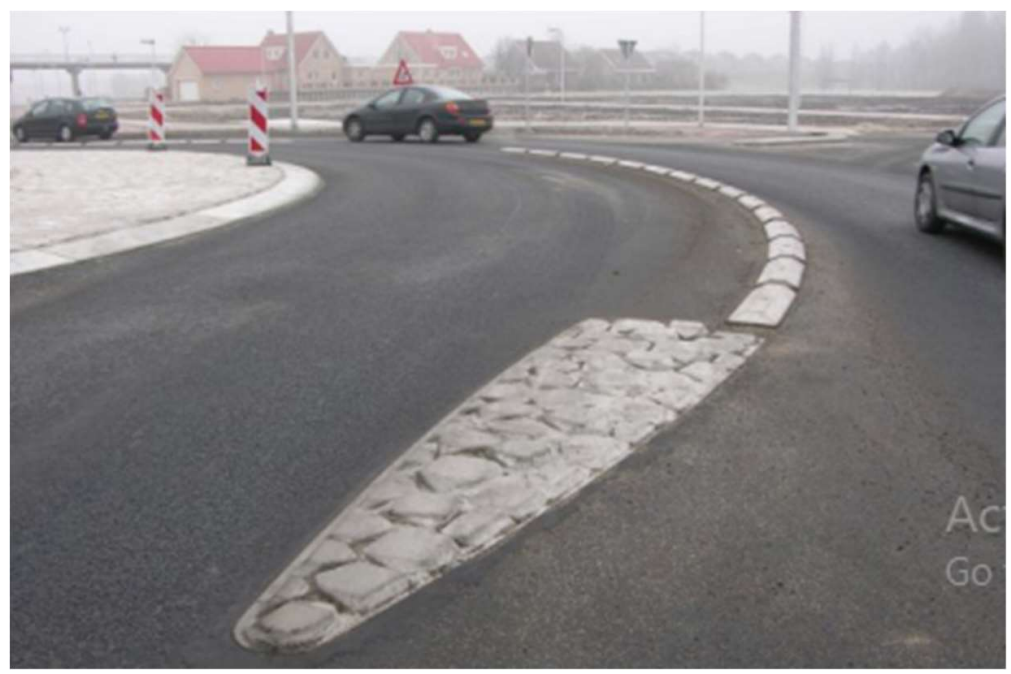

Figure 13: Raised Mountable dividers((Tollazzi \& Engineering, 2014)

On turbo roundabouts there should be traversable beginning as suggested by Dutch guidelines. This geometric feature prevents the inadmissible traffic flow which is further going to weaving on inner circulatory roadway.
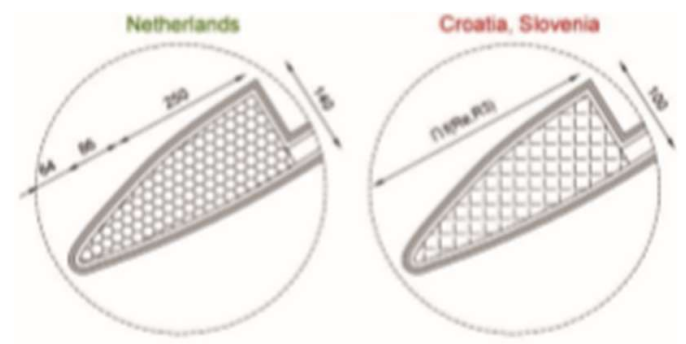

Figure 14: Traversable beginning on a mountable lane divider(Džambas et al., 2017)

The length of the mountable divider as suggested by Dutch guidelines should be $4 \mathrm{~m}$. In Croatian and Slovenian guidelines length of the mountable divider is not defined; there it is defined by the curvature of the entry curve radii and outer circulatory lane inner radii. The latter design approach is more feasible because it gives designer an independence to choose a length of mountable divider according to the swept path of the design vehicle. The opening width of inner circulatory roadway is not defined by any design guideline. Studies have shown that the opening width depends on the swept path, minimum clearances, inner circular radius and lane divider i.e. median width (Džambas et al., 2017). 


\subsubsection{Additional geometric elements added on Turbo Roundabout}

\subsubsection{Pedestrian Crossing}

Many Dutch Turbo Roundabouts have two-stage pedestrian and cyclist crossing on approaches to roundabout. This two-stage crossing is also used by cyclist, although pedestrians and cyclists are segregated as we can see in fig 15.

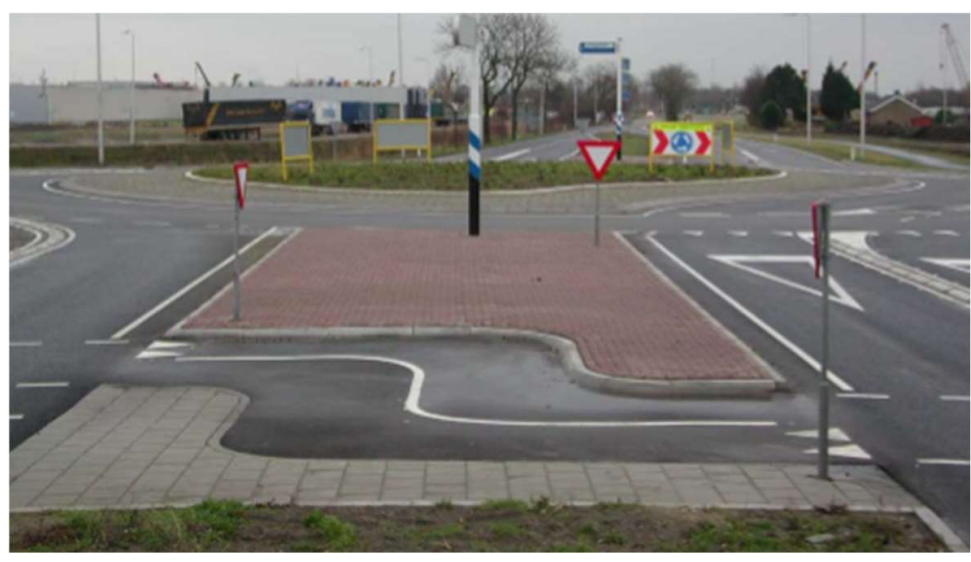

Figure 15: Two stage pedestrian and cyclist((Murphy \& Manager, 2015)

\subsubsection{Small island Diverter}

After some experience with turbo roundabout, an issue was raised. The issue was that motorists were attempting to turn left and travel in clockwise direction especially elderly people who were not able to focus on signs and symbols of road. To solve this problem a small diverter island with no left turn sign was added to turbo roundabout which provided a visual glue for drivers to turn right rather than left. Also, no further incorrect turns were made on roundabout as observed by engineers in Canada. 


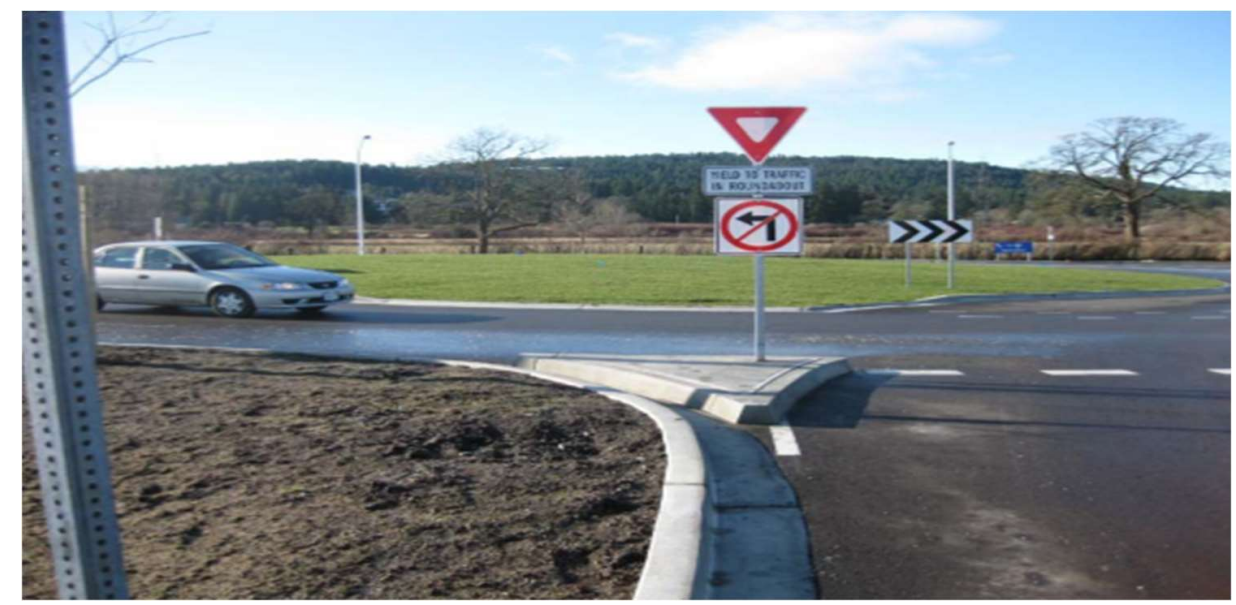

Figure 16: small island diverter

\subsubsection{Turbo Block}

The first part of making a turbo-roundabout is generation of turbo-block. A turbo block is supplementary, or guideline construction used in the design of turbo-roundabout. It is a foundation stone on which turbo-roundabout is based. The features of the turbo block give us an illusion that it would be spiral curve but instead it is a spiral-circulatory geometry consisting of two semicircles with different centres. The type of turbo roundabout mentioned in article 2.2.1 is defined by the type of turbo block; an egg roundabout has two starting spirals, rotor turbo roundabout has four starting spirals and the knee turbo roundabout which is our case have one starting spiral.(Gaspar, 2013). The turbo block also has a primary translation axis which is a hypothetical line usually at some angle with $\mathrm{Y}$-Axis i.e. $\theta \mathrm{T}$ which serves as the border between the two semi-circles. It is designed in such a way that circular arcs at one side of translation axis overlap with circular arcs on other side. Guidelines for predefined templates of turbo roundabouts are provided by major developing European nations such as Netherlands, Croatia, Slovenia and Germany. Based on these guidelines of predetermined templates the turbo block can be classified into two groups; Group 1 will be consisting of guidelines provided by Dutch, Croatian and Slovenia whilst Group 2 will describe the guidelines provided by German documents. 


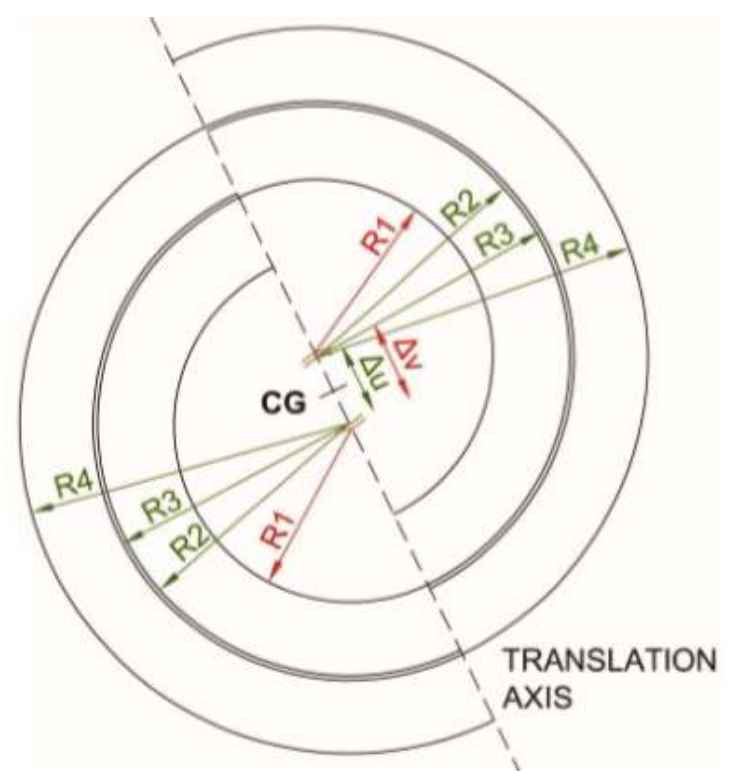

Figure 17: Turbo Block for Dutch, Croatian and Slovenia(Džambas et al., 2017)

The templates provided by these three countries consist of four circular arcs with larger radii of successive arcs. There are four centres and all of them lie on translation axis (Fig 17) Roundabout curves $R_{1}$ and $R_{2}$ represent the inward and the external edge of the internal circulatory roadway $L_{1}$, while circular curves $R_{3}$ and $R_{4}$ represent the inward and the external edge of the external circulatory roadway $\mathrm{L}_{2}$ (Serbian Authority for Roads, Beograd, 2012) (CROW, 2008).

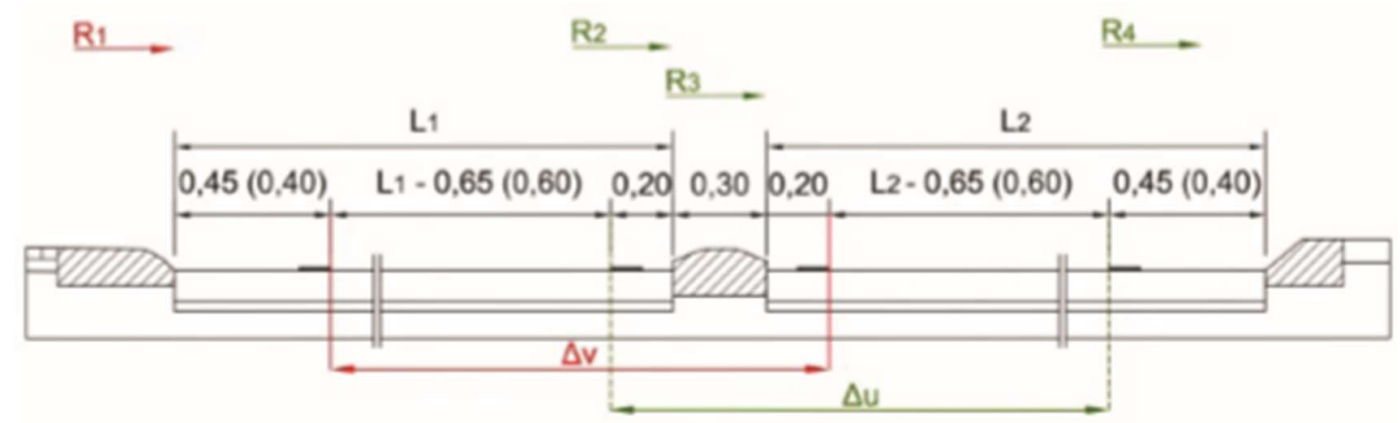

Figure 18:Cross section of Turbo Block Dutch, Croatian and Slovenia(Džambas et al., 2017)

The Dutch guideline suggests that the template of turbo roundabout should be chosen by fastest path vehicle speed and the optimum value of inner roundabout radius depends upon the dimension of splitter island (CROW, 2008). The guideline suggests that for $3 \mathrm{~m}$ and $7 \mathrm{~m}$ splitter island the value of inner roundabout radius is $12 \mathrm{~m}$ and $15 \mathrm{~m}$ respectively; smaller inner radii are recommended but 
larger inner radii can be used when traffic flow demands. Furthermore, there is a shift observed " $\mathrm{f}$ " between the circular arcs, the shift is there due to narrow width of marginal strips and can be eliminated by widening marginal strips as done by Croatian guideline. The position of translation axis recommended by these countries guidelines is "five minutes until five" for four-leg intersections and "ten past eight" for three-leg intersections (Ministry of Transport Republic of Slovenia, 2011)

German guideline is somewhat simpler; the turbo block in German guideline suggests three pair of circular arcs and two centres on translation axis. One of centre represents circular arcs at one side of primary translation axis and other centre represent circular arcs of other side of primary translation axis. No widening is provided for German turbo-block, the width is persistent throughout. The turbo block also do not provide any template and advise that circulatory lane, width and other geometric features depends upon design vehicle and swept path of the vehicle; although it recommends the range of diameter from $45 \mathrm{~m}$ to $70 \mathrm{~m}$. The position of translation axis according to German document is an iterative process which depends on design vehicle and position of approaches (FGSV, 2015).

\subsubsection{Movement of traffic flow in turbo roundabouts}

Not much has been mentioned in the studies about the movement of traffic flow in turbo roundabouts, which may be due to the simple and understandable mechanics of it. Although it is recommended that we provide signage as during driving on turbo roundabouts, it is very critical which lane to choose depending upon the destination.(Gaspar, 2013)
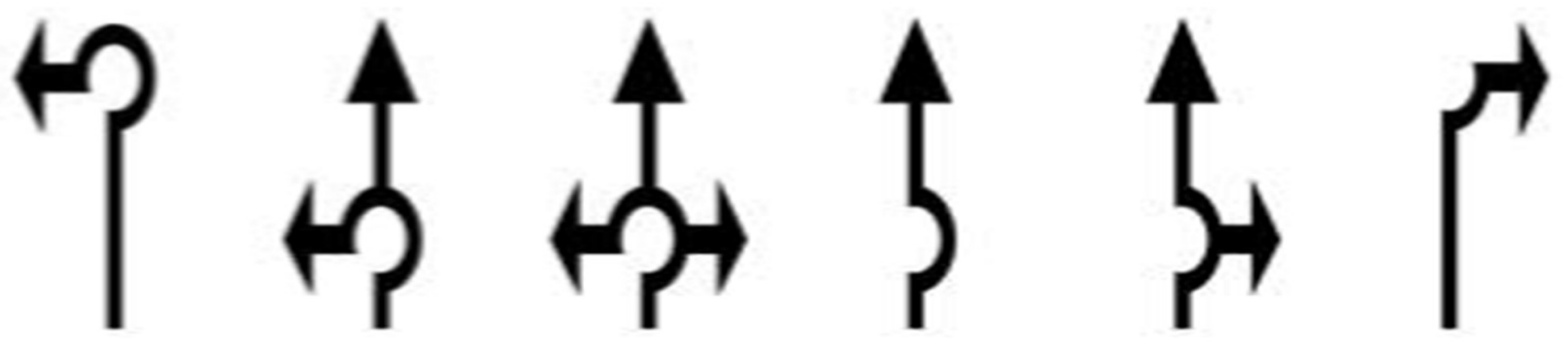

Figure 19: Signage (Gaspar, 2013)

Fig 19 demonstrates movement of a vehicle from approach 1 to all other approaches and movement from other approaches will be similar. 
An important aspect of movement of vehicles at turbo-roundabouts is the swept path of the vehicle. This swept path helps us to decide the radius of the turbo block and show us that the vehicle is safe to manoeuvre through that intersection. Referring to table 4; heavy vehicles which included "Long combination vehicles" i.e. WB-20D, WB-30T and articulated buses i.e. A-BUS were analysed on Auto-Turn Pro. Using Auto-Turn Pro we observed the swept path of the vehicles and following results were obtained.

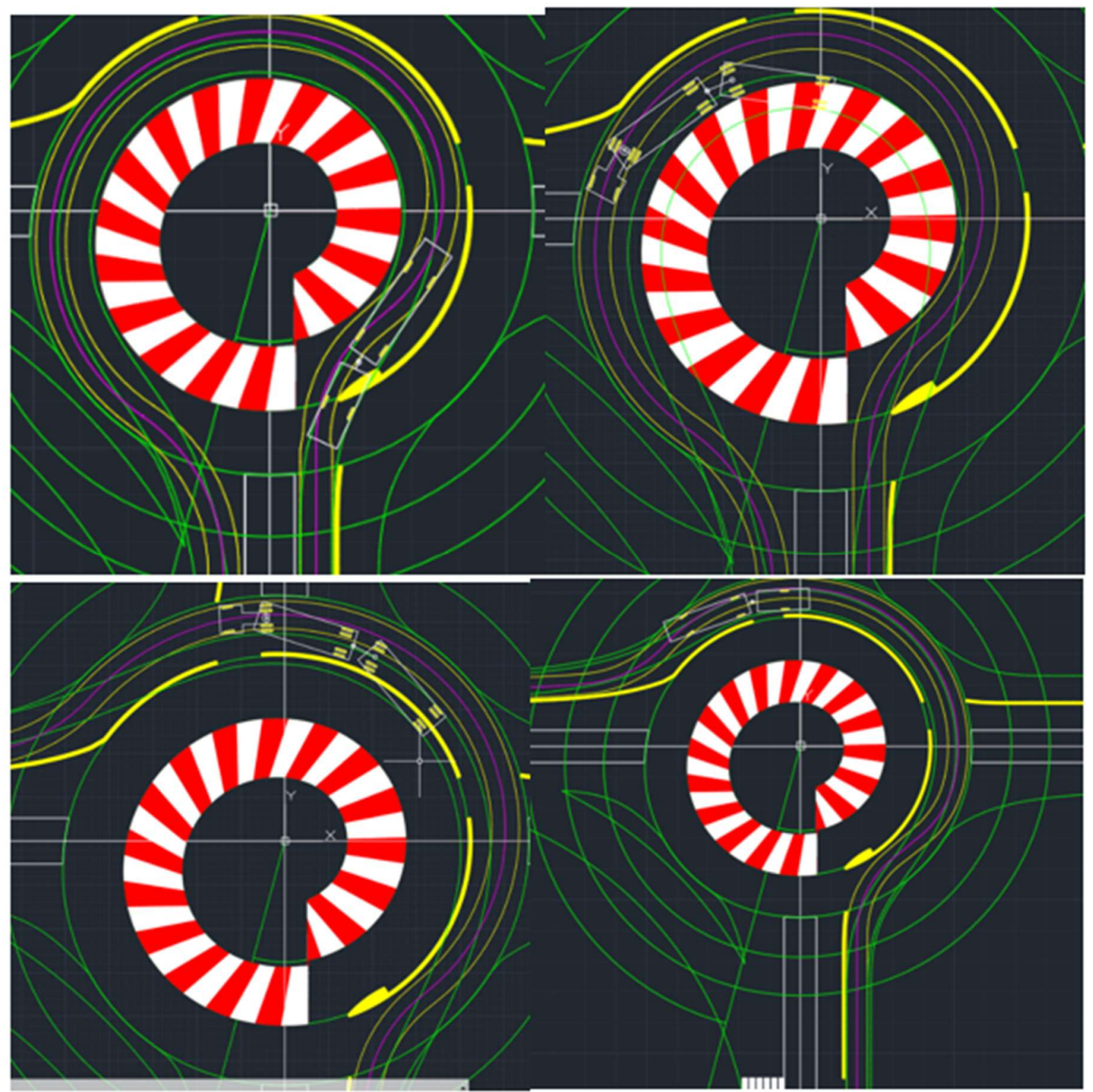

Figure 20: Swept path of the vehicles clockwise A-BUS at inner circulatory lane, WB-20D at inner circulatory lane, A-BUS at outer circulatory lane, WB-20D outer circulatory lane 
As we can see in fig-20 that both long combination vehicles i.e. WB-20D and articulated buses i.e. A-BUS can manoeuvre safely but take space of geometric feature such as raised mountable divider and truck apron. As shown in fig-20; WB-20D used truck apron at inner circulatory lane and raised mountable divider while travelling outer circulatory lane. Whilst A-BUS never stepped on truck apron at inner circulatory lane but it used raised mountable divider that also just at start to enter the opening. Study by (Gazzarri, A., Pratelli, A., Souleyrette, R. R., \& Russell, E. R.) confirms that for heavy vehicles especially for turbo roundabouts these features are required as high occupancy vehicles requires additional turning space as compared to passenger car. So long combination vehicles and articulated buses can manoeuvre safely due to the geometric feature of raised mountable divider and truck apron. 


\subsection{Sight Distance}

Sight distance is an integral part while designing any intersection. Sight distance is the distance available for the driver to safely drive the vehicle so that he can see the stationary or moving objects and will allow doing the safe manoeuvre. Sight distance at roundabouts is provided to enable a driver without the right of way to enter a roundabout traffic flow in secure manner. Geometric elements of roundabouts are of key importance in providing sight distance(Washington State Department ofTransportation, 2017). At roundabouts the important sight distances which will influence its design are-:

- Stopping sight distance

- Intersection sight distance.

\subsection{Stopping Sight Distance in Roundabouts}

Stopping sight distance (SSD) is the minimum sight distance available on a highway at any spot having sufficient length to enable the driver to stop a vehicle travelling at design speed, safely without collision with any other obstruction. The sight distance ensures that a driver can clearly see the obstacles or potentially conflicting vehicles. Sight distance at unsignalized intersection i.e. roundabouts is provided to enable a driver to enter a roundabout traffic flow without the right of way in secure manner; so the geometric elements of roundabouts are of key importance in providing sight distance. Sight distance can be defined the distance that allows the driver to stop safely if something happens unexpectedly. Stopping sight distance is the sum of the distance travelled during the perception time, reaction time and the breaking distance. For a levelled road this is obtained by equating the work done in stopping the vehicle and the kinetic energy of the vehicle. Stopping sight distance should be measured assuming driver eye height $3.54 \mathrm{ft}$ and an assumed object height of $1.97 \mathrm{ft}$ according to (AASHTO), 2004) There are 3 critical locations according to mentioned references in which we must check stopping sight distances for roundabouts -:

- Approach Sight Distance

- Exit Cross Walk Sight Distance

- Circulatory Sight Distance 


\subsubsection{Approach sight distance}

It is the stopping sight distance required for the approaching vehicle before entering the roundabout. Approach sight distance is analysed when a vehicle is at the approach curve i.e. perpendicular to the tangent of the inscribed circle. On deeply analysing the approach sight distance it is further subdivided into two sections that is sight distance to crosswalk and sight distance to yield line.(USDOT, 2017)

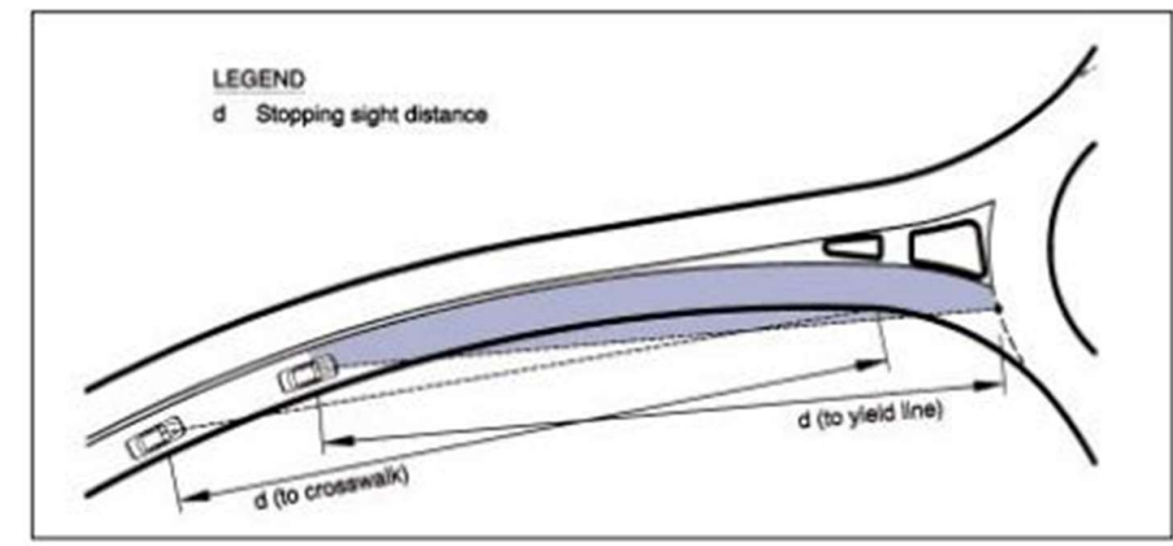

Figure 21: Approach sight distance (USDOT, 2017))

\subsubsection{Exit crosswalk sight distance}

It is the stopping sight distance needed towards the crosswalk on exit of the circulatory roadway. A cross walk sight distance is critical for pedestrians and is assumed to be perpendicular to the curve and is computed for both entry and exit of the vehicle(USDOT, 2017) 


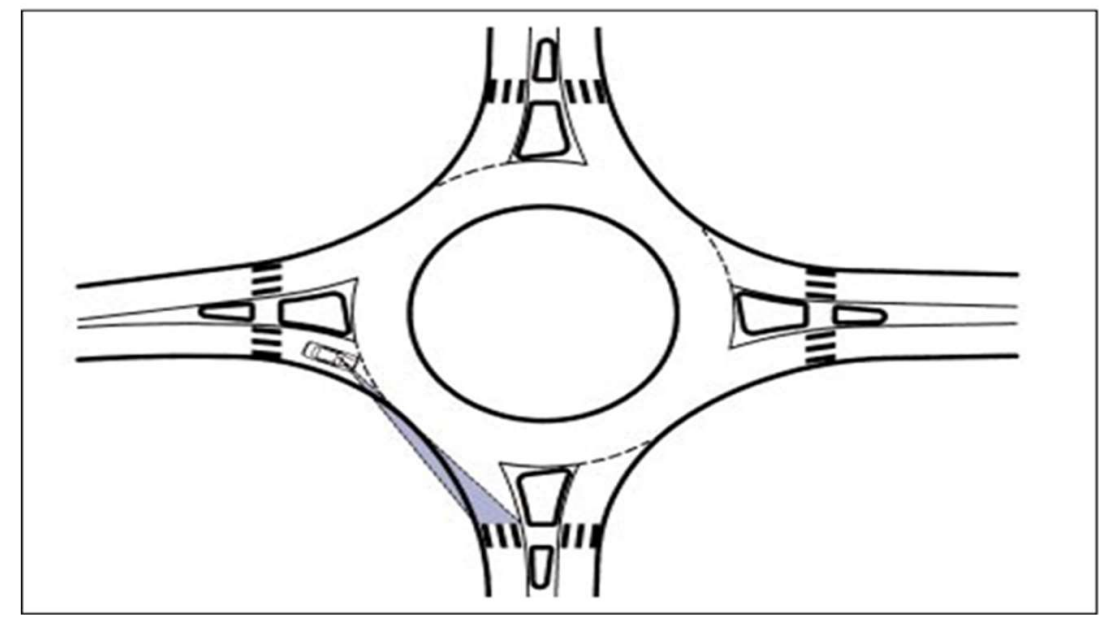

Figure 22: Exit cross walk sight distance (USDOT, 2017)

\subsubsection{Circulatory sight distance}

It is the stopping sight distance required on the circulatory roadway to drive the vehicle safely. The circulatory sight distance is important as the driver must pay attention to the left roundabout quadrant, to safely drive and driver also needs to have an adequate sight distance in front of vehicle. The design stopping sight distance is measured along the vehicle's path as it follows the curvature of the roadway and is not measured as a straight line. So this is the reason for using stopping sight distance on the curves and not on straight paths.

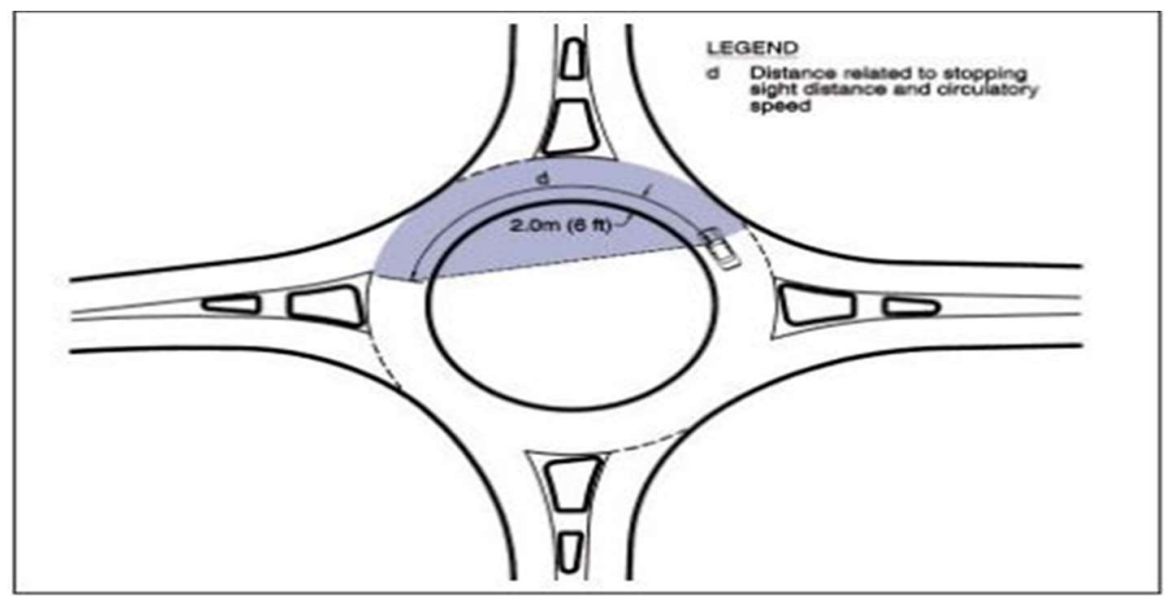

Figure 23: Circulatory sight distance (USDOT, 2017) 


\subsubsection{Formulation of Stopping sight distance}

The stopping sight distance for US Department of Transportation is given by the equation 1 described below. The stopping sight distance should be measured using driver eye height of 1,080 $\mathrm{mm}(3.54 \mathrm{ft})$ and height of object of $600 \mathrm{~mm}(1.97 \mathrm{ft})$ in accordance with AASHTO "Green Book. The same stopping sight distance is used in approach sight distance, exit crosswalk sight distance and circulatory sight distance. The only difference observed is speed. For approach sight distance we will take entry speed of vehicle; for circulatory sight distance we will take circulatory speed. The interesting part is exit crosswalk sight distance in which case we take entry speed only because the exit speed is governed by the entering speed of vehicle.

Equation 1: Stopping Sight Distance (USDOT, 2017)

$$
d=(0.278)(t)(V)+0.039 \frac{V^{2}}{a}
$$

where:

$$
\begin{aligned}
& \mathrm{d}=\text { stopping sight distance, } \mathrm{m} \text { : } \\
& \mathrm{t}=\text { perception-brake reaction time, assumed to be } 2.5 \mathrm{~s} \\
& \mathrm{~V}=\text { initial speed, } \mathrm{km} / \mathrm{h} \text {; and } \\
& \mathrm{a}=\text { driver deceleration, assumed to be } 3.4 \mathrm{~m} / \mathrm{s}^{2} .
\end{aligned}
$$

\subsection{Intersection Sight Distance in roundabouts}

Intersection sight distance is the distance required for a vehicle that does not have the right of way to ensure that the driver can see and safely react to the conflicting vehicles. Intersection crashes are mainly caused due to inadequate sight distance at intersections. Therefore, building roundabouts instead of intersections reduces number of conflicting points, in conclusion reduces accident rates. However, providing adequate sight distance at roundabouts to manoeuvre the vehicle safely is considered an important factor.

For intersection sight distance, we provide a clear view of traffic for the entering vehicle to the circulating roadway to perceive and react to the acceptable gap. Intersection sight distance is calculated through the establishment of adequate sight lines that allows a driver to see and safely 
react to the conflicting vehicles. The sight triangles also help drivers of conflicting vehicles to see the approaching vehicles.

The required sight distance in roundabouts is achieved through the same method which we applied in four-legged intersections i.e. the sight triangle method. The sight triangles are provided and checked at each entry. Intersection sight distance is a main part of establishing a safe roundabout. Meanwhile, it has been proved by the researchers that more intersection sight distance resulted in higher vehicle speed and thus by affecting the safety of the roundabout so close attention must be given to ensure that does not happen.

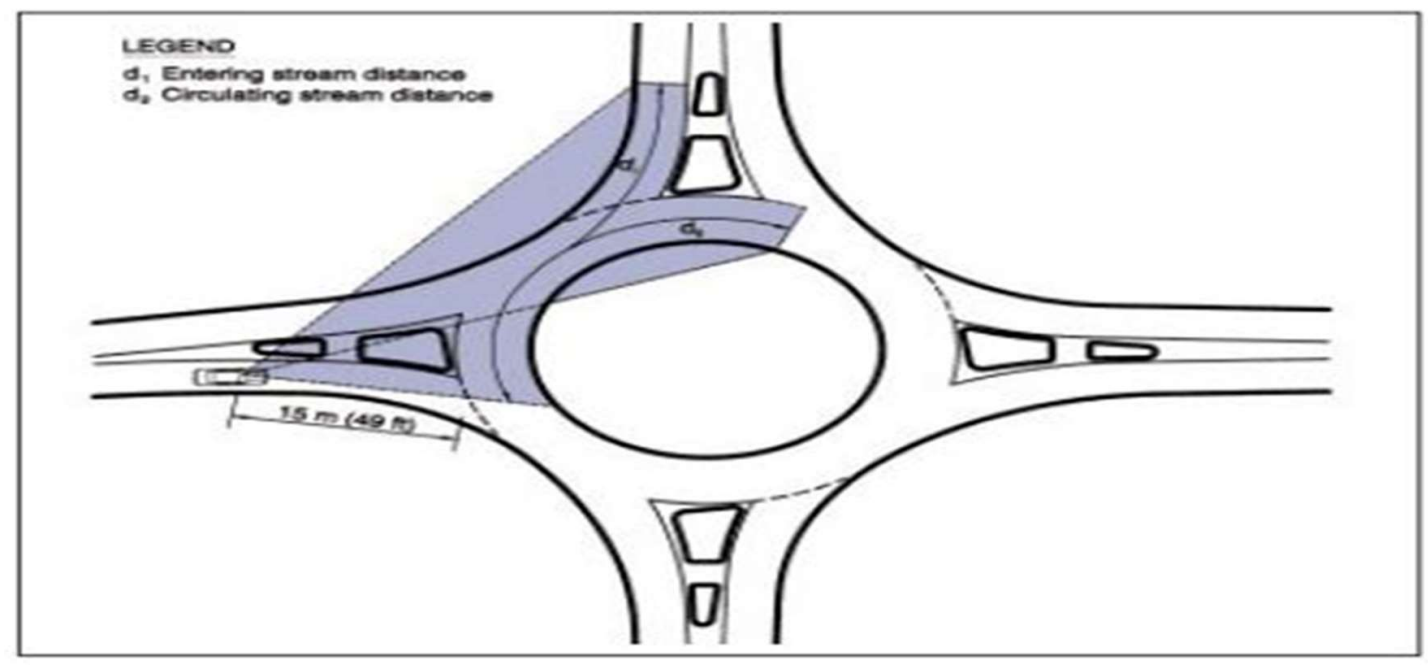

Figure 24: Intersection sight distance (USDOT, 2017)

\subsubsection{Formulation of Intersection Sight Distance}

Intersection sight distance should be measured using driver height of $1,080 \mathrm{~mm}(3.54 \mathrm{ft})$ and an object height of 1,080 mm (3.54 ft) as stated by AASHTO. The sight distance "triangle" has two conflicting approaches that must be checked independently. The first conflicting approach is the

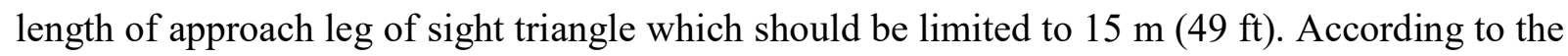
USDOT guidelines it is necessary to restrict this sight distance to minimum requirements using landscaping. The second conflicting approach is when a vehicle approaching an entry to roundabout faces conflicting vehicles within the circulatory roadway. In this case the USDOT have 
given an empirical formula which gives us the length of conflicting leg of sight triangle for a given design speed. Sight distance at roundabouts is derived for two cases. The first one is entering stream, it comprises of vehicles from the immediate upstream entry. The speed for this movement can be approximated by taking the average of the entry path speed (path with radius $\mathrm{R}_{1}$ ) as shown in below diagram and the circulating path speed (path with radius $\mathrm{R}_{2}$ ). The second is circulating stream, it comprises of vehicles that entered the roundabout prior to the immediate upstream entry. This speed can be approximated by taking the speed of left turning vehicles (path with route having radius $\mathrm{R} 4)$.

Equation 2: Intersection Sight Distance (USDOT, 2017)

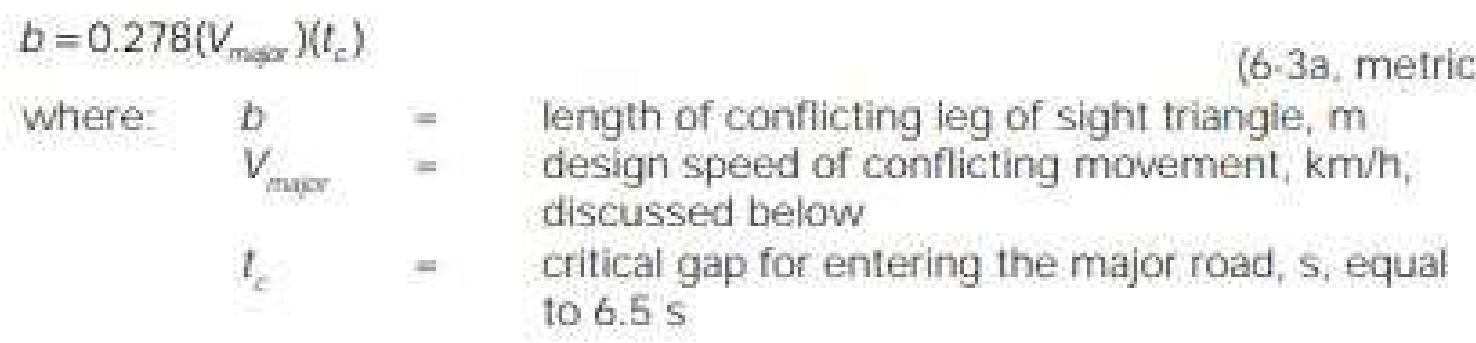

Entering stream $=0.5$ (the entry path speed (path with radius $\mathrm{R}_{1}+$ circulating path speed (path with radius $R_{2}$ )

Circulating Stream $=$ speed of left turning vehicles (path with radius $\mathrm{R}_{4}$ )

The critical gap i.e. 6.5 seconds is based on the total time required for a passenger car to turn right while requiring the conflicting stream vehicle to slow no less than 70 percent of initial speed. Passenger cars are assumed to be as critical design vehicle for intersection sight distance. Furthermore $6.5 \mathrm{sec}$ is also valid for single-unit and combination truck speeds that are at least 10 $\mathrm{km} / \mathrm{h}$ and 15 to $20 \mathrm{~km} / \mathrm{h}$ slower than passenger cars. The formula for conflicting approach has been applied for different speeds and is formulated into a given table below: 
Table 4: Conflicting approach speed and its corresponding distances

\begin{tabular}{ll}
\hline $\begin{array}{l}\text { Conflicting } \\
\text { Approach Speed } \\
(\mathbf{k m} / \mathrm{h})\end{array}$ & $\begin{array}{l}\text { Computed } \\
\text { Distance }(\mathrm{m})\end{array}$ \\
\hline 20 & 36.1 \\
\hline 25 & 45.2 \\
\hline 30 & 54.2 \\
\hline 35 & 63.2 \\
\hline 40 & 72.3 \\
\hline
\end{tabular}

\begin{tabular}{ll}
\hline $\begin{array}{l}\text { Conflicting } \\
\text { Approach Speed } \\
\text { (mph) }\end{array}$ & $\begin{array}{l}\text { Computed } \\
\text { Distance (ft) }\end{array}$ \\
\hline 10 & 95.4 \\
\hline 15 & 143.0 \\
\hline 20 & 190.1 \\
\hline 25 & 238.6 \\
\hline 30 & 286.3 \\
\hline
\end{tabular}

It is advisable to provide no more than the minimum required intersection sight distance on each approach. Excessive intersection sight distance can lead to higher vehicle speeds that reduce the safety of the intersection for all road uses. The height of Central Island and other landscaping techniques control the intersection sight distance.

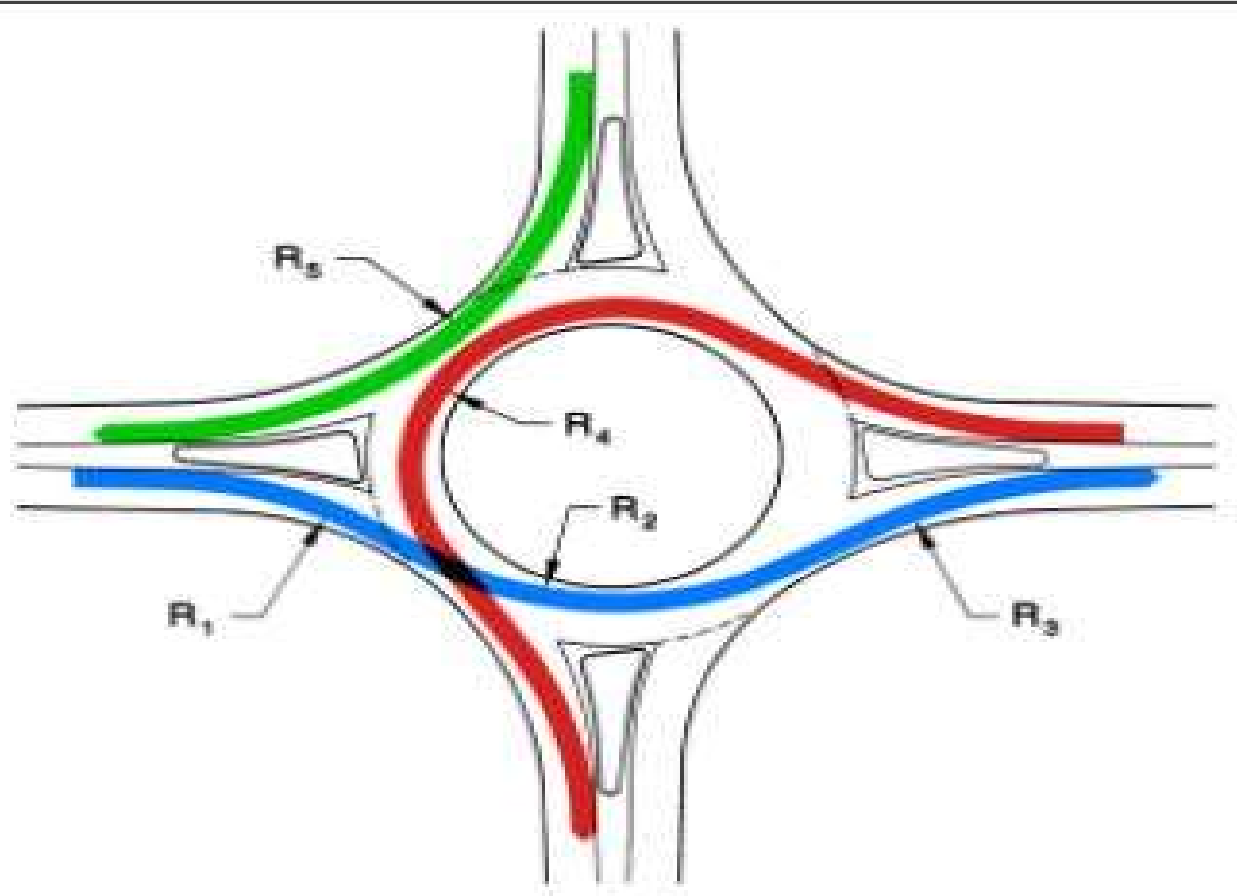

Figure 25 : Intersection sight distance on roundabouts in USDOT 


\subsection{Intersection Sight Distance at Turbo Roundabouts (Graphical Representation)}

At turbo roundabouts when we plot the sight distance, it comes same as in modern lane roundabouts. Sight-lines are drawn from approaching vehicle at approach leg to the entering and circulating vehicle. During my research I drew sight-line in AutoCAD using the add-on software called "Torus". In the below figures i.e. figure 26, the paper is showing the Intersection sight distance at turbo roundabouts from "AutoCAD". In fig 26 the red and white hatched portion is the truck apron and yellow shaded potion shows the raised mountable divider. Vehicle is shown at different approaches; the light blue lines emerging from the vehicle are the sight lines for intersection sight distance. The dashed pink line shows the vehicle path movement of entering conflicting vehicle and circulating conflicting vehicle. Sight lines are drawn to a point, where distance is measured from conflict point as starting point, the equation for that stopping sight distance is given by equation 2. At Approach 1 and Approach 2 simple sight-lines are formed just like in the modern roundabouts, but at Approach 3 and Approach 4 sight lines are formed are little bit different. The sight-lines at approach 3 and approach 4 have two sight-lines for both circulatory and entering vehicle; the reason behind this is there are two conflicting vehicles which are going to crash with entering vehicle. Out of these two sightlines the sightline that is selected for design purpose is the one that covers more area; for example, at approach 3 and approach 4 the outer entering lane covers up more area hence that sight-line is selected. In case of circulating vehicle outer circulatory vehicle sightline covers more area in case of approach 3 while inner circulatory vehicle sight-line is selected as guiding sightline in case of approach 4 . The approach 2 and approach 1 do not have two sight-lines because in approach 1 there is a bypass lane due to which vehicle entering from approach 2 and going right does not conflict whereas when approach vehicle is at approach 2, the entering vehicle surpasses and do not conflict due to raised mountable dividers. 

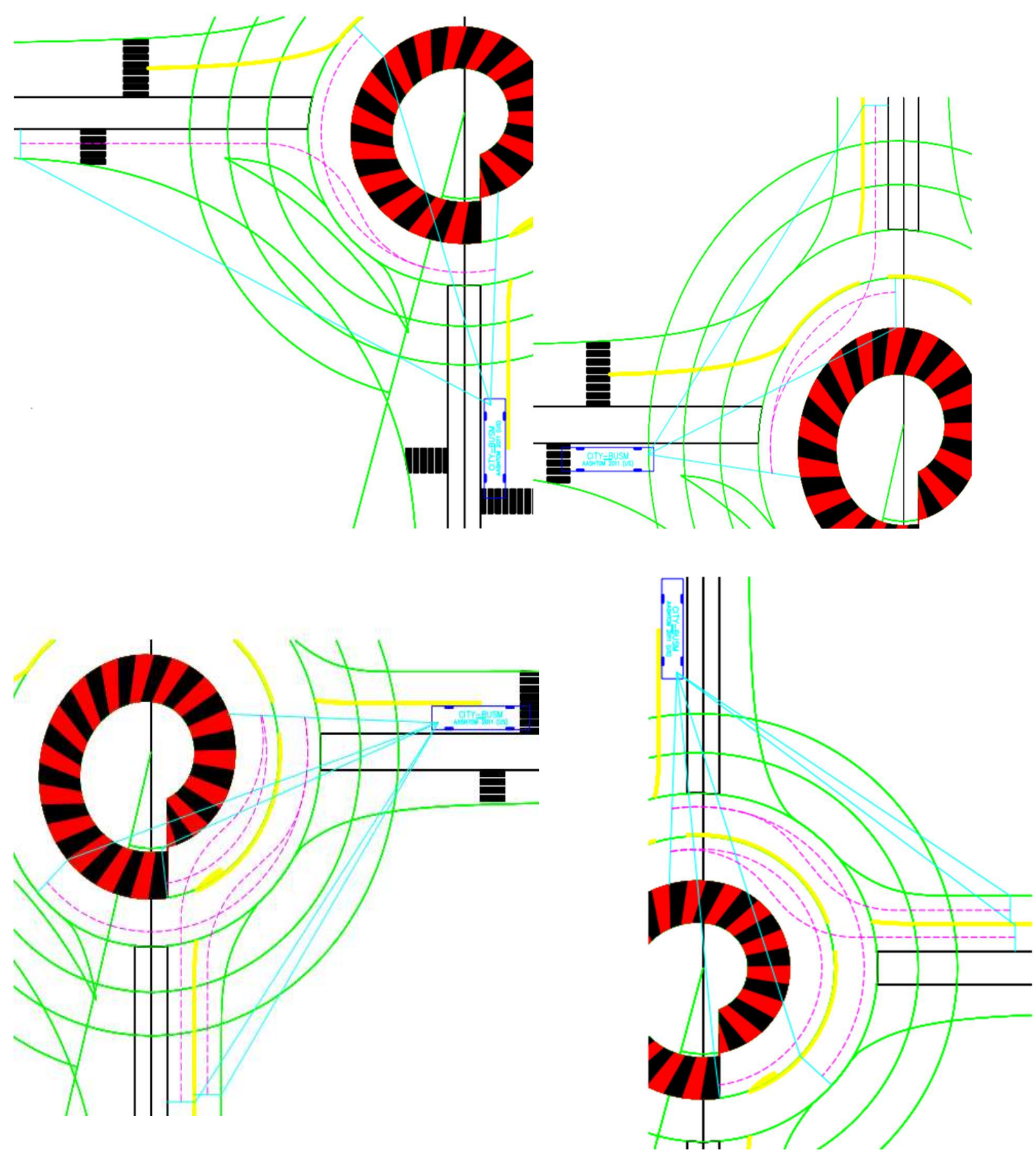

Figure 26: Sight Distances at all approaches. Approach 1, Approach 2, Approach 3, Approach 4 clockwise 


\subsection{Analytical Approach to Intersection Sight Distance}

As previously discussed in intersection sight distance we provide entering vehicles a clear view of traffic on the circulating roadway to perceive and react to an acceptable gap. Intersection sight distance is achieved through the establishment of adequate sight lines that allow a driver to see and safely react to potentially conflicting vehicles. As done in article 3.3; ISD can be plotted and found out by graphical method and that has been the conventional method. An analytical model is developed in this paper in next few articles using coordinate geometry and mathematical equations. Similar type of analytical models were developed for clearance needs with similar type of methods for vehicles at different types of intersections; for example (Ali et al., 2009; Easa and Ali, 2006; Easa et al., 2004; McCoy et al., 2001; Joshua and Saka,1992) and for pedestrians at railway crossings (Easa et al. 2017), Design guideline for symmetrical single lane roundabout based on Intersection sight distance(Said M. Easa, 2017). According to (Džambas et al., 2017) the driver has to see both conflicting vehicles i.e. circulating and entering vehicles from the left quadrant. The visibility distance for circulating vehicles is based on $5 \mathrm{sec}$ gap and we will consider the same $5 \mathrm{sec}$ gap for turbo-roundabout. According to the Australian guidelines (Austroads 2009) the visibility depends on the Inscribed circle diameter.

The (USDOT, 2017) suggests checking the sight distance Lmin (15 m) from the yield line, but (Said M. Easa, 2017) argue to check the sight distance at yield line too. Similar to (Said M. Easa, 2017) suggestion Australian guidelines also check sight distance visibility at both these locations i.e. at yield line and at $15 \mathrm{~m}$ from yield line (Akçelik, 2014).

\subsection{Methodology}

The procedure behind developing these equations for any type of turbo roundabout involves certain processes. These different processes are here summarised in a form of method through which anyone can develop these analytical equations. The steps are-:

1. Develop a turbo block outline with one primary translation axis for a central island of random radius. 
2. Analyse the swept paths of the design vehicle along different route i.e. while the vehicle is circulating and whilst vehicle is entering at an entry radius.

3. Using the swept path determine the central island radius and type of turbo roundabout and design the turbo block.

4. Repeat the procedure if needed for different design vehicles.

5. After your turbo roundabout is determined the first step towards analysing ISD (Intersection Sight Distance) is finding the coordinates of centre of the arcs on the lefthand side and right-hand side of the translation axis. The coordinates for right hand side semicircles are assumed to be at origin.

6. After we have determined the centre of semicircles on both sides of translation axis, the next step would be finding the coordinates of approach vehicle. The first case will be when approach vehicle will be at $\mathrm{L}$ min $(15 \mathrm{~m})$ distance from yield line.

7. Finding coordinates of conflict point is the next step. Determination of coordinates of conflict point is very important because, the coordinates of this point can help us to determine the coordinates of conflicting circulating and conflicting entering vehicles. The scope of this study is limited to only conflicting circulating vehicles, so paper will focus on just that.

8. Using equation 2 position of circulating vehicle is determined and simultaneously its coordinates are determined.

9. Using the coordinates of approach vehicle and coordinates of circulating vehicle, an equation for clearance is developed which changes with the circulating speed i.e. Vc.

10. For the second case when approach vehicle is at yield line, we first find coordinates of approach vehicle like step 6 .

11. The coordinates of conflict point remain same as it conflicts point does not change.

12. Now repeat the steps 8 and 9 i.e. coordinates of circulating vehicles are determined.

13. To find maximum clearance use the equation developed in step 9 and optimize it between the suitable limits. 


\subsection{Assumptions}

The following assumptions were made while developing the analytical model-:

1. The centre for arcs on the right-hand side is at origin.

2. The approach legs are intersecting the turbo roundabout at 90-degree angle.

3. The $t_{\mathrm{c}}$ for intersection sight distance is $5 \mathrm{sec}$.

4. Distance from the front end and driver's eye distance is assumed to be $2.43 \mathrm{~m}$ or 7.97 feet.

5. For simplicity of the study we either put turbo roundabout upside down on traditional Cartesian coordinate system or arrange coordinate system upside down (Fig 27).

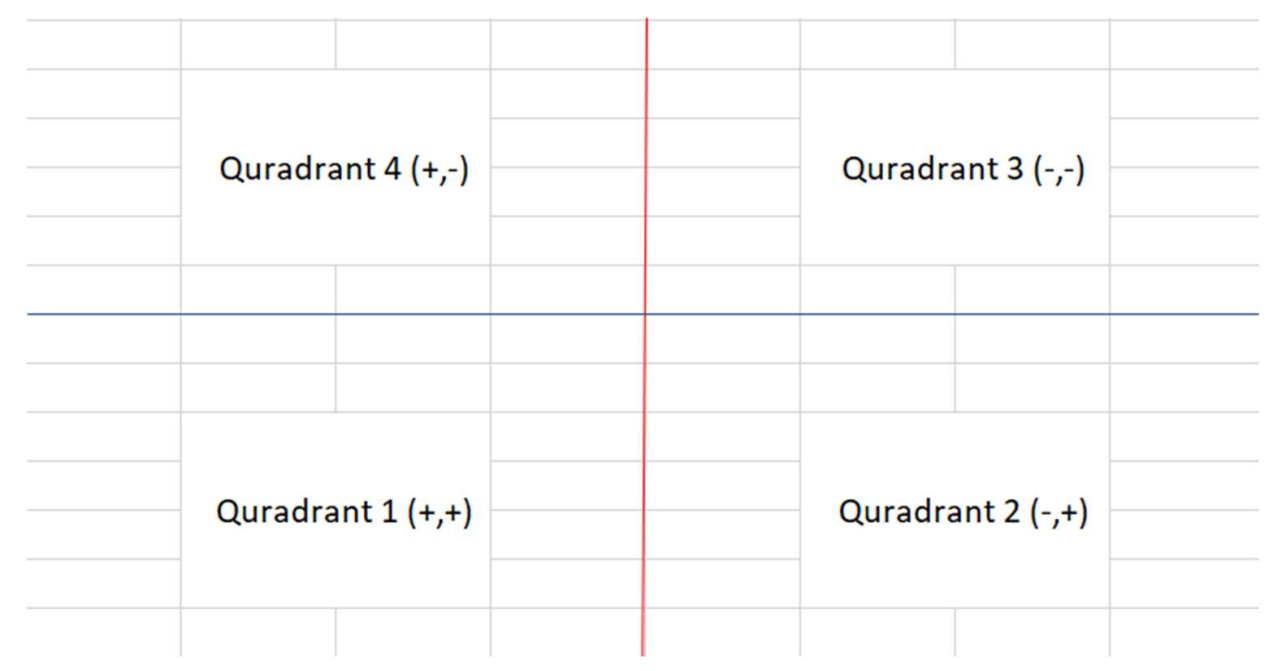

Figure 27:Assumption 4

\subsection{Development of turbo block}

In our case we have taken knee type roundabout with a $10.50 \mathrm{~m}$ radius with a primary translation axis at 15 degrees or $\theta$ т. Although (Murphy \& Manager, 2015) suggests that the translation axis angle should depend on the swept of the vehicle and should be an iterative process but using the current fleet of large vehicles 15 degrees has somewhat became a constant in all the turbo blocks. Relation between different radii of turbo-block has been derived during further discussion below: The procedure of transitioning from turbo-block to turbo roundabout consists of adding a truckapron and adding approach legs. By constructing the width of apron according to Dutch guideline 
a shift is observed between inner and outer truck apron. This shift is observed to be $5 \mathrm{~cm}$ and is denoted by a constant "f" (Džambas et al., 2017). The width of a circulatory roadway is denoted by " $\mathrm{W}_{\mathrm{c}}$ ". The initial radius is the outer radius of the truck apron and the inner radius of inner circulatory lane. In all the given templates of turbo block the inner radius value is given i.e. " $\mathrm{R}_{1}$ " is given and we can choose the width of circulatory roadway depending on the swept path of the vehicle (T CROW,2008).

Using these values of " $\mathrm{R}_{1}$ ", $\mathrm{W}_{\mathrm{c}}$ " and " $\mathrm{f}$ " we can develop the radius for other circles. To develop the radius of other circles we will use the relation

$\left(D_{2}-D_{1}=W_{c}+f\right)$

Where, "D" is the diameter of a specific semicircle. On closely observing the turbo-block we noted that it has many different semi-circles but only two centres; one is for all the semi-circles on right hand side of the translation axis and one for all the semi-circles on right hand side of the translation axis which can be clearly shown in the fig (28). The difference between the two centres when measured is approximately equal to half of the circulatory roadway width i.e. " $\mathrm{W}_{\mathrm{c}} / 2$ ". For an initial radius of " $\mathrm{R}_{1}$ " $10.50 \mathrm{~m}$, the other radius using the relation above equation 3 are formatted in form of below table.

Table 5:Different radius of turbo block

\begin{tabular}{|c|c|}
\hline $\mathrm{R}_{1}$ & $10.50 \mathrm{~m}$ \\
\hline $\mathrm{R}_{2}$ & $13.29 \mathrm{~m}$ \\
\hline $\mathrm{R}_{3}$ & $16.08 \mathrm{~m}$ \\
\hline $\mathrm{R}_{4}$ & $18.87 \mathrm{~m}$ \\
\hline $\mathrm{R}_{5}$ & $21.66 \mathrm{~m}$ \\
\hline
\end{tabular}

After laying the turbo-block approach legs are added on each side of the turbo block to carve into a turbo-roundabout. The approach legs are then added at an exactly 90-degree angle along the roundabout as suggested by (Džambas et al., 2017). 


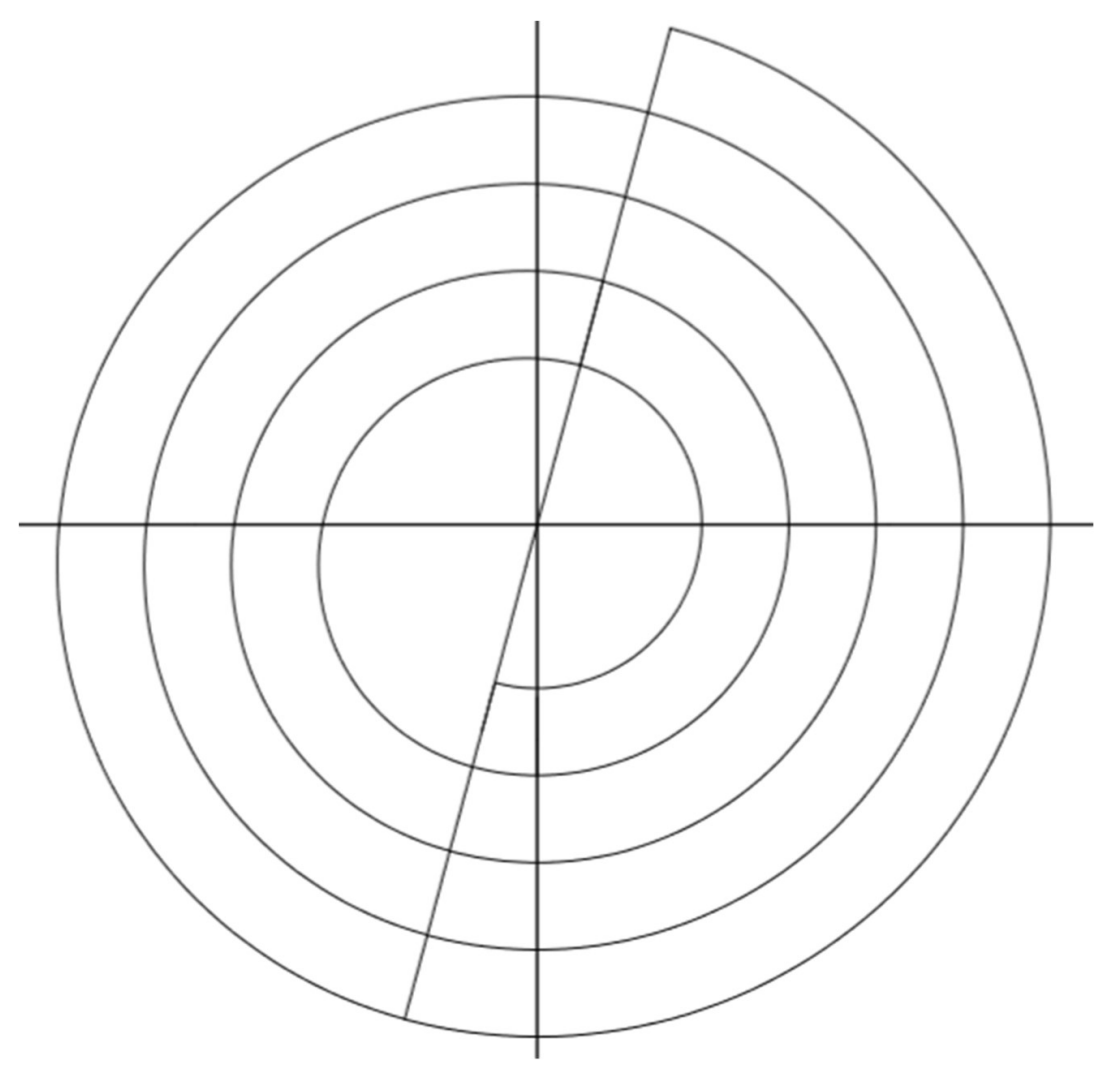

Figure 28: Generation of Turbo block

\subsection{Coordinates of Significant points}

\subsubsection{Coordinates of New Centre}

The new centre which is at $0.5 \mathrm{~W}_{\mathrm{C}}$ distance from the origin i.e. $\mathrm{O}_{1}$ along the translation axis is named as " $n$ " with coordinates as $\left(\mathrm{X}_{\mathrm{n}}, \mathrm{Y}_{\mathrm{n}}\right)$. Referring to fig 28 we know $\theta_{\mathrm{T}}$ and distance $\mathrm{W}_{\mathrm{c}}$. The value of new coordinates will remain unchanged for all cases. Using the tools of trigonometry, the coordinates of new centre with respect to origin can be found out as follows -: 


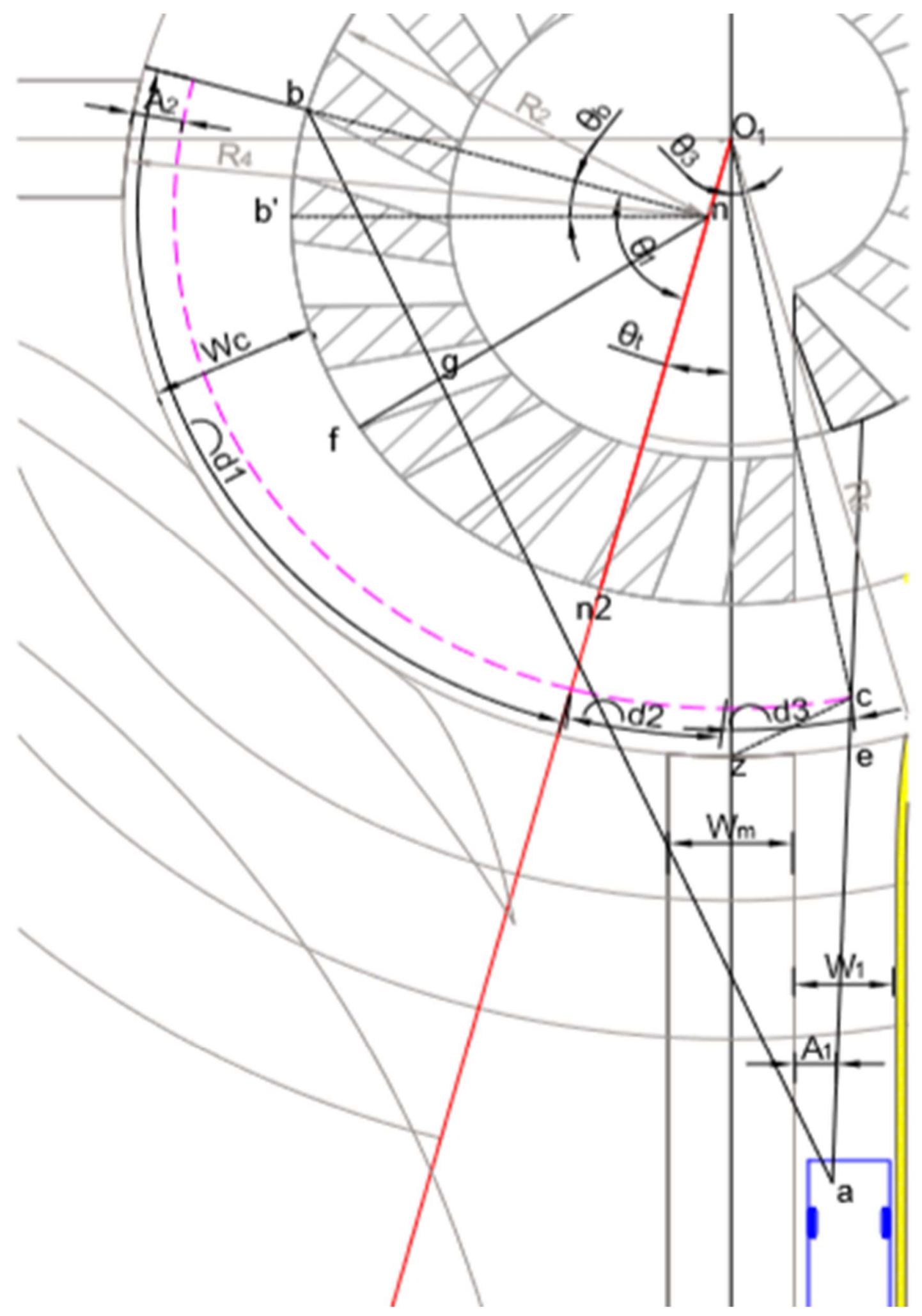

Figure 29: Significant points at turbo roundabout 
Now "n" is new centre,

Its coordinates are found from right angle triangle $O_{1} n n_{1}$

$x_{n}=\left(O_{1} n\right) \sin \theta_{T}$

$=\frac{W_{c}}{2} \operatorname{Sin} \theta_{T}$

$y_{n}=\left(O_{1} n\right) \cos \theta_{T}$

$\frac{W_{c}}{2} \operatorname{Cos} \theta_{T}$

\subsubsection{Case -1 (Approach vehicle $15 \mathrm{~m}$ before yield line)}

Following the standards set by (USDOT, 2017),(Said M. Easa, 2017) we first measure the sight distance at $15 \mathrm{~m}(\mathrm{~L} \mathrm{~min})$ from yield line. The driver eye at $15 \mathrm{~m}$ from yield line is named as point "a" i.e. position of approach vehicle. From this point the vehicle will move towards the centre of the entry lane "W1" so that it can comfortably take turns either to circulatory lane "W $\mathrm{C}$ ". This centre of the lane is named as "e". There is median separating the entry and exit lanes; and the centre of the median when intersects with $\mathrm{R}_{5}$ the point is named as " $\mathrm{z}$ ". The width of the median is named as " $\mathrm{W}_{\mathrm{m}}$ ", Interestingly the nature of turbo roundabout is such as that the $\mathrm{Y}$ axis exactly passes through the centre off the median. The difference between the driver eye and edge of circulatory roadway is " $\mathrm{A}_{2}$ " and difference between the driver eye and outer edge of median is “A $\mathrm{A}_{1}$ ". From fig (29) we take $\mathrm{R}_{5}$ i.e. radius of inscribed circle diameter with the centre as origin.

Coordinates of Approach Vehicle

$x_{a}=\frac{W_{m}}{2}+W_{1}-A_{1}$

$y_{a}=R_{5}+L_{\min }$

\section{Coordinates of Conflict Point}

To find the coordinates of conflict point we first must find coordinates of point "e" i.e. $x_{e}, y_{e}$

$x_{e}=\left(\frac{W_{m}}{2}+\frac{W_{1}}{2}\right)$

$y_{e}=\sqrt{R_{5}^{2}-\left(\frac{W_{m}}{2}+\frac{W_{1}}{2}\right)^{2}}$ 
$\operatorname{Or}\left(R_{5}{ }^{2}-\left(\frac{W_{m}}{2}+\frac{W_{1}}{2}\right)^{2}\right)^{0.5}$

Now to find coordinates of point $C$,

Let coordinates be $x_{c}, y_{c}$

As point 'c' lies on extension of line 'ae' and both 'ae' and 'ac' must have same slopes therefore equation of line 'ac' with $x_{c} \& y_{c}$ satisfying it is as follows:

$x_{c}=x_{a}+\frac{\left(y_{c}-y_{a}\right)}{P_{a c}}$

Where $P_{a c}=\frac{y_{e}-y_{a}}{x_{e}-x_{a}}$

Here $\mathrm{P}_{\mathrm{ac}}$ is slope of line 'ac' or 'ae'.

Now in order to find coordinates of point ' $c$ ' we see that circle of radius $\mathrm{R}_{5}$ intersects the line 'ac' at 'c'.

Equation of circle with center as $\mathrm{O}_{1}(0,0)$ and radius $\mathrm{R}_{5}$ with $x_{c} \& y_{c}$ satisfying it is

$x_{c}{ }^{2}+y_{c}{ }^{2}=\left(R_{5}-A_{2}\right)^{2}$

Therefore, their point of intersection $x_{c} \& y_{c}$ is found out as follows:

Putting $x_{c}=x_{a}+\frac{\left(y_{c}-y_{a}\right)}{P_{a c}}$ i.e. putting equation (8) into equation (9).

$\left(x_{a}\right)^{2}+\frac{\left(y_{c}-y_{a}\right)^{2}}{P_{a c}^{2}}+\frac{2 x_{a}\left(y_{c}-y_{a}\right)}{P_{a c}}+y_{c}^{2}=\left(R_{5}-A_{2}\right)^{2}$

Converting it into quadratic form for solution of $y_{c}$

$\left(x_{a}\right)^{2}+\frac{y_{c}{ }^{2}}{P_{a c}{ }^{2}}+\frac{y_{a}{ }^{2}}{P_{a c}{ }^{2}}-\frac{2 y_{c} y_{a}}{P_{a c}{ }^{2}}+\frac{2 x_{a}\left(y_{c}-y_{a}\right)}{P_{a c}}+y_{c}{ }^{2}=\left(R_{5}-A_{2}\right)^{2}$

$y_{c}^{2}\left[\frac{1}{P_{a c}{ }^{2}}+1\right]+y_{c}\left[\frac{-2 y_{a}}{P_{a c}{ }^{2}}+\frac{2 x_{a}}{P_{a c}}\right]+\left[\frac{y_{a}^{2}}{P_{a c}{ }^{2}}-\frac{2 x_{a} y_{a}}{P_{a c}}-\left(R_{5}-A_{2}\right)^{2}\right]=0$

Thus, this is quadratic equation in $y_{c}$ i.e.

$$
a y_{c}^{2}+b y_{c}+c=0
$$

Where

$$
\begin{aligned}
& a=\left[\frac{1}{P_{a c}{ }^{2}}+1\right] \\
& b=\left[\frac{-2 y_{a}}{P_{a c}{ }^{2}}+\frac{2 x_{a}}{P_{a c}}\right]
\end{aligned}
$$


$c=\left[\frac{y_{a}^{2}}{P_{a c}{ }^{2}}-\frac{2 x_{a} y_{a}}{P_{a c}}-\left(R_{5}-A_{2}\right)^{2}\right]$

Solving values for "a", "b", "c" and substituting in solution of quadratic equation

$y_{c}=\frac{-b \pm \sqrt{b^{2}-4 a c}}{2 a}$

we can find $y_{c}$, This gives us two values. It is important to take care that we are interested in only those values which correspond to quadrant in which conflict point lies.

substituting values of $y_{c}$ in equation 9 ,

$x_{c}^{2}+y_{c}^{2}=\left(R_{5}-A_{2}\right)^{2}$ or $x_{c}=\left\{\left(R_{5}-A_{2}\right)^{2}-y_{c}{ }^{2}\right\}^{0.5}$

Thus, we can find $x_{c}$ i.e. equation 12 .

\section{Coordinates of Circulating Vehicle}

To find the coordinates of circulating vehicle, we first need to locate position of circulating vehicle for which we will use equation 2. From equation 2 we will get the total distance 'd' travelled by the vehicle in ' $t_{c}$ ' seconds. The total ' $d$ ' can be divided into three parts i.e. ' $d_{1}$ ', ' $d_{2}$ ', ' $d_{3}$ ' depicted in figure (29). ' $d_{3}$ ' distance covered by vehicle between point ' $c$ ' and ' $z$ ' and make an angle of $\theta_{3}$. The ' $\mathrm{d}_{2}$ ' is the distance covered along arc subtended by the angle $\theta_{T}$ and ' $\mathrm{d}_{3}$ ' is the rest of the distance which can be found out by subtracting ' $\left(d_{1}+d_{2}\right)$ ' from total distance ' $d$ '.

Total travelling distance $=d=d_{1}+d_{2}+d_{3}=0.278 V_{c} \mathrm{t}_{\mathrm{c}}$

The target is to find coordinate of point $\mathrm{b}$ and for this $\theta_{b}$ is required to be found.

For this angle $b^{\prime} n n_{2}=90^{\circ}-\theta_{T}$, where 90 is in degrees it can also be represented as radians as done in application example

and $\theta_{b}=\theta_{1}-$ angle $b^{\prime} n n_{2}$

$=\theta_{1}-\left(90-\theta_{T}\right)$

Hence,

$\theta_{b}=\frac{d_{1}}{\left(R_{4}-A_{2}\right)}-\left(90-\theta_{T}\right)$

As we have already discussed $d_{1}$ can be found as follows: 


$$
\begin{aligned}
d_{1}=d-\left(d_{2}+d_{3}\right) & \\
& \\
d_{2} & =\theta_{T} \times\left(R_{5}-A_{2}\right) \\
d_{3} & =\theta_{3} \times\left(R_{5}-A_{2}\right)
\end{aligned}
$$

We need to find $\theta_{3}$ for knowing $d_{3}$ see figure (29)

Join 'c \& ' $\mathrm{z}$ '. Now in triangle $O_{1} c Z$

$$
\begin{gathered}
O_{1} c=R_{5}-A_{2} \\
O_{1} z=R_{5} \\
z c=\text { distance between coordinate of } z \& c=\sqrt{\left(x_{z}-x_{c}\right)^{2}+\left(y_{z}-y_{c}\right)^{2}}
\end{gathered}
$$

Coordinates of $\mathrm{z}$ are

$$
\begin{gathered}
x_{z}=0 \\
y_{z}=R_{5}
\end{gathered}
$$

Coordinates of 'c' can be had from the value of $\mathrm{x}_{\mathrm{c}} \& \mathrm{y}_{\mathrm{c}}$ from solution of equation $11 \& 12$ Filling these values in equation (17) ' $z c$ ' can be found.

\section{Now}

In triangle $O_{1} C Z$

$\operatorname{Cos} \theta_{3}=\frac{\left(R_{5}-A_{2}\right)^{2}+R_{5}{ }^{2}-2(z c)^{2}}{2\left(R_{5}-A_{2}\right) R_{5}}$

or $\theta_{3}=\cos ^{-1}\left[\frac{\left(R_{5}-A_{2}\right)^{2}+R_{5}^{2}-2(z c)^{2}}{2\left(R_{5}-A_{2}\right) R_{5}}\right]$

Then $d_{3}=\theta_{3} \times\left(R_{5}-A_{2}\right) \& d_{2}=\theta_{T} \times\left(R_{5}-A_{2}\right)$

$\& d_{1}$ can be known as

$d_{1}=d-\left(d_{2}+d_{3}\right)$

After finding $d_{1}$, substitute the value of $d_{1}$ in equation (12)

$\theta_{b}=\frac{d_{1}}{\left(R_{4}-A_{2}\right)}-\left(90-\theta_{T}\right) ; \theta_{b}$ can be found out.

Thus, coordinates of $b$

$$
\begin{aligned}
& x_{b}=\left(R_{2}\right) \cos \theta_{b}+\frac{W_{c}}{2} \sin \theta_{T} \\
& y_{b}=-\left(R_{2}\right) \sin \theta_{b}+\frac{W_{c}}{2} \cos \theta_{T}
\end{aligned}
$$




\subsubsection{Case 2 (Approach Vehicle at yield line)}

For case 2 as mentioned in methodology only the coordinates of approach vehicle changes, the rest of the equations remain same. The equations for coordinates of conflict point and the coordinates of circulating vehicle does not change as they are independent of the coordinate value of approach vehicle. The parameter that will vary will be clearance and maximum clearance. As the front end of the vehicle will approach yield line, there will be certain distance from the front end and driver's eye. As stated in assumptions this distance is assumed to be $2.43 \mathrm{~m}$ or 7.97 feet. The coordinates of approach vehicle will be -:

$x_{a}=\left(\frac{W_{m}}{2}+\frac{W_{1}}{2}\right)$

$y_{a}=R_{5}+7.97$ feet

\subsection{Guideline for Lateral Clearance}

Lateral Clearance is the distance required without any sight obstruction so that approach vehicle can see the possible conflict vehicle. the total area covered under this distance is known as clear zone ; in fig(24) light blue shaded zone implies clear zone.(USDOT, 2017) recommended that we should not provide more than required clearance otherwise it can lead to higher crash frequency. To control the required or maximum clearance, (Said M. Easa, 2017) recommends planting trees or fence or any kind of landscape technique which can act as a guideline for sight line. Also(USDOT, 2017) give us restriction over height of central island and landscaping on central island in the clear zone. Although outside of clear zone higher landscaping increase safety as it impacts psychologically to drivers to reduce the vehicle speed.

\subsubsection{Defining Clearance}

The formulation of lateral clearance depends on the coordinates of the approach and the circulating conflicting vehicles both of which can be found out by equations 19,20,4,5. Considering an arbitrary Point $f$ on the edge of the truck apron $\left(x_{f}, y_{f}\right)$, a point " $\mathrm{g}$ " is determined where line "ab" 
intersects "nf".Now that the points are set, we can establish that the lateral clearance is equal to distance "gf".

Slope of line 'nf' is

$P_{n f}=\frac{y_{f}-y_{n}}{x_{f}-x_{n}}$

and equation of line $n f$ is-:

$y=y_{n}+P_{n f}\left(x-x_{n}\right)$

$y=\frac{y_{f}-y_{n}}{x_{f}-x_{n}}\left(x-x_{n}\right)+y_{n}$

Similarly Slope of line 'ab' is

$P_{a b}=\frac{y_{b}-y_{a}}{x_{b}-x_{a}}$ and $\mathrm{e}$

equation of line ' $a b$ ' is-:

$y=y_{a}+P_{a b}\left(x-x_{a}\right)$

$y=y_{a}+\left(\frac{y_{b}-y_{a}}{x_{b}-x_{a}}\right) \times\left(x-x_{a}\right)$

Lines having equations at (24) \& (26) intersect at unique point ' $\mathrm{g}$ ' the coordinates of which can be found out by simultaneously solving these equations

So equating Eq (24) and Eq (26) (x,y can be found which gives values of $x_{g}, y_{g}$ ),

Therefore, $y_{n}+P_{n f}\left(x_{g}-x_{n}\right)=y_{a}+P_{a b}\left(x_{g}-x_{a}\right)$

$$
x_{g}\left(P_{n f}-P_{a b}\right)=x_{n} P_{a b}+x_{n} P_{n f}+y_{a}-y_{n}
$$

Or $x_{g}=\frac{y_{a-} y_{n}-x_{a} P_{a b}+x_{n} P_{n f}}{P_{n f}-P_{a b}}$

Putting value of eq (27) into eq (24)

$y_{g}=y_{n}+P_{n f}\left(x_{g}-x_{n}\right)$

$y_{g}=y_{n}+P_{n f}\left[\left(\frac{y_{a}-y_{n}-x_{a} P_{a b}+x_{n} P_{n f}}{P_{n f}-P_{a b}}\right)-x_{n}\right]$

$y_{g}=y_{n}+\frac{P_{n f}}{P_{n f}-P_{a b}}\left[y_{a}-y_{n}-x_{a} P_{a b}+x_{n} P_{n f}-x_{n} P_{n f}+x_{n} P_{a b}\right]$

$y_{g}=\frac{y_{a} P_{n f}-y_{n} P_{a b}-\left(x_{a}-x_{n}\right) P_{n f} P_{a b}}{P_{n f}-P_{a b}}$ 
Therefore, for finding clearance we put value from equation 27 and equation 28 into equation 29 we get lateral clearance at a point " $\mathrm{f}$ ".

$\mathrm{C}_{\mathrm{f}}=$ Lateral Clearance $=g f=\left(R_{2}\right)-\sqrt{\left(x_{g}-x_{n}\right)^{2}+\left(y_{g}-y_{n}\right)^{2}}$

\subsubsection{Maximum Clearance}

Note that "f" point is variable and the coordinate value of point " $g$ " depends on coordinate value of " $\mathrm{f}$ ". To find the maximum clearance i.e. $\mathrm{C}_{\mathrm{f}(\mathrm{MAX})}$ we need to locate point "f" multiple time and evaluate the maximum clearance. As doing this task manually is a challenge, the study used excel add in tool called "Solver". In solver we optimize the maximum clearance within the upper and lower limits.

The following charts try to show the maximum clearance at different radius and different circulating speeds which are found by the excel tool "Solver". Excel Solver uses simple optimization model

Maximize $Z=C_{f}$

Subject to

$$
d_{L}<d_{f}<d_{U}
$$

where $d_{f}=$ distance of Point $f$ on the edge of truck apron (decision variable), $d_{L}$ and $d_{U}=$ arbitrary lower and upper limits of the decision variable, that cover possible range of lateral clearance.

\subsubsection{Design Aids}

Using equation 30 and 31 , table 7 and table 8 are formulated where for different circulating speeds maximum clearance is found out for radius $10.50 \mathrm{~m}$ and radius $12 \mathrm{~m}$. Then the fig 30 and fig 31 shows the relation between circulating vehicle speed and maximum clearance. As shown in both the graphs; for any radius the clearance increases with the circulating speed. The slope obtained for both radius and both the cases are nonlinear functions although clearance obtained; when vehicle is at yield line is more in contrast to vehicle is $15 \mathrm{~m}$ before yield line for both any radius. Bar chart 32 reinforce the above two stated facts i.e. as circulating speed increases, clearance 
increases, and clearance is also more when vehicle is at yield line is in contrast to vehicle is $15 \mathrm{~m}$ before yield line. The bar chart 32 also shows the fact that despite any speed, larger the radius less will be the clearance for both cases.

The findings obtained from this graph were similar to that found by (Said M. Easa, 2017) where in case of multi-lane symmetrical roundabout the maximum clearance at yield line were larger and maximum clearance at larger radius roundabouts were less.

Table 6: Maximum Clearance at variable speeds for radius $10.50 \mathrm{~m}$

\begin{tabular}{|r|r|r|r|r|r|}
\multicolumn{7}{|c|}{ RADIUS 10.50 OR 34.45} \\
\hline & & \multicolumn{2}{|c|}{ AT 15m below yeild line } & \multicolumn{2}{c|}{ At yield line } \\
\hline VC(MPH) & VC(KMHR) & Clearance(ft) & Clearnce(m) & Clearance(ft) & Clearnce(m) \\
\hline 10 & 16.094 & 0.0155 & 0.0047244 & 1.819 & 0.5544312 \\
\hline 13 & 20.9222 & 3.1901 & 0.97234248 & 7.3219 & 2.2317151 \\
\hline 15 & 24.141 & 7.6602 & 2.33482896 & 12.2809 & 3.7432183 \\
\hline 17 & 27.3598 & 13.4482 & 4.09901136 & 17.9793 & 5.4800906 \\
\hline 19 & 30.5786 & 20.2069 & 6.15906312 & 24.23 & 7.385304 \\
\hline 21 & 33.7974 & 27.6549 & 8.42921352 & 30.8971 & 9.4174361 \\
\hline 23 & 37.0162 & 35.5468 & 10.8346646 & 37.8146 & 11.52589 \\
\hline
\end{tabular}

Table 7: Maximum Clearance at variable speeds for radius $12 \mathrm{~m}$

\begin{tabular}{|r|r|r|r|r|r|}
\hline \multicolumn{5}{|c|}{ RADIUS 12m QR 39.37 feet } \\
\hline & & \multicolumn{2}{|c|}{ AT 15m below yeild line } & \multicolumn{2}{c|}{ At yield line } \\
\hline VC(MPH) & VC(KMIHR) & Clearance(ft) & Clearnce(m) & Clearance(ft) & Clearnce(m) \\
\hline 10 & 16.094 & 0 & 0 & 1.3325 & 0.406146 \\
\hline 13 & 20.9222 & 2.175 & 0.66294 & 6.2667 & 1.9100902 \\
\hline 15 & 24.141 & 6.0231 & 1.83584088 & 10.8674 & 3.3123835 \\
\hline 17 & 27.3598 & 11.2454 & 3.42759792 & 16.234 & 4.9481232 \\
\hline 19 & 30.5786 & 17.5087 & 5.33665176 & 22.195 & 6.765036 \\
\hline 21 & 33.7974 & 24.5527 & 7.48366296 & 28.6284 & 8.7259363 \\
\hline 23 & 37.0162 & 32.1585 & 9.8019108 & 35.3954 & 10.788518 \\
\hline
\end{tabular}


Maximum Clearance for Radius $10.50 \mathrm{~m}$

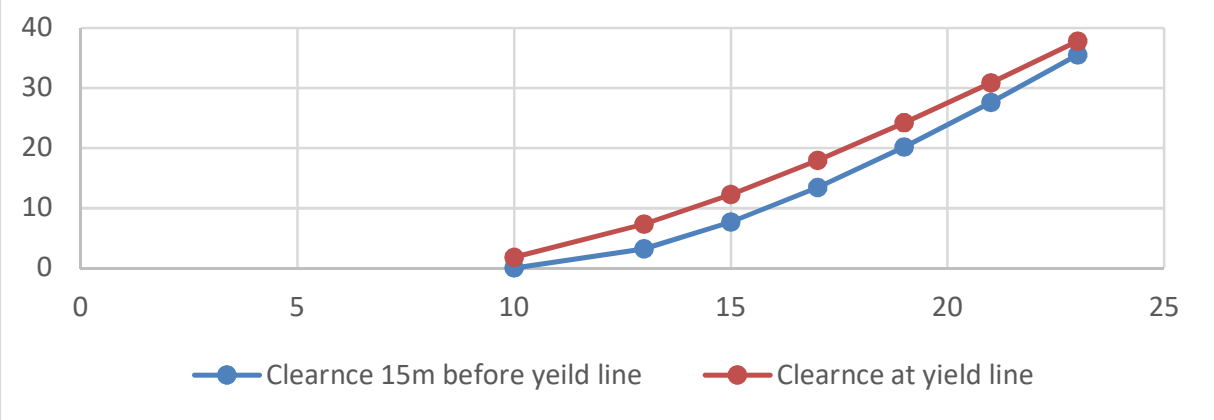

Figure 30:Graphical representation of clearance at different speeds for radius $10.50 \mathrm{~m}$

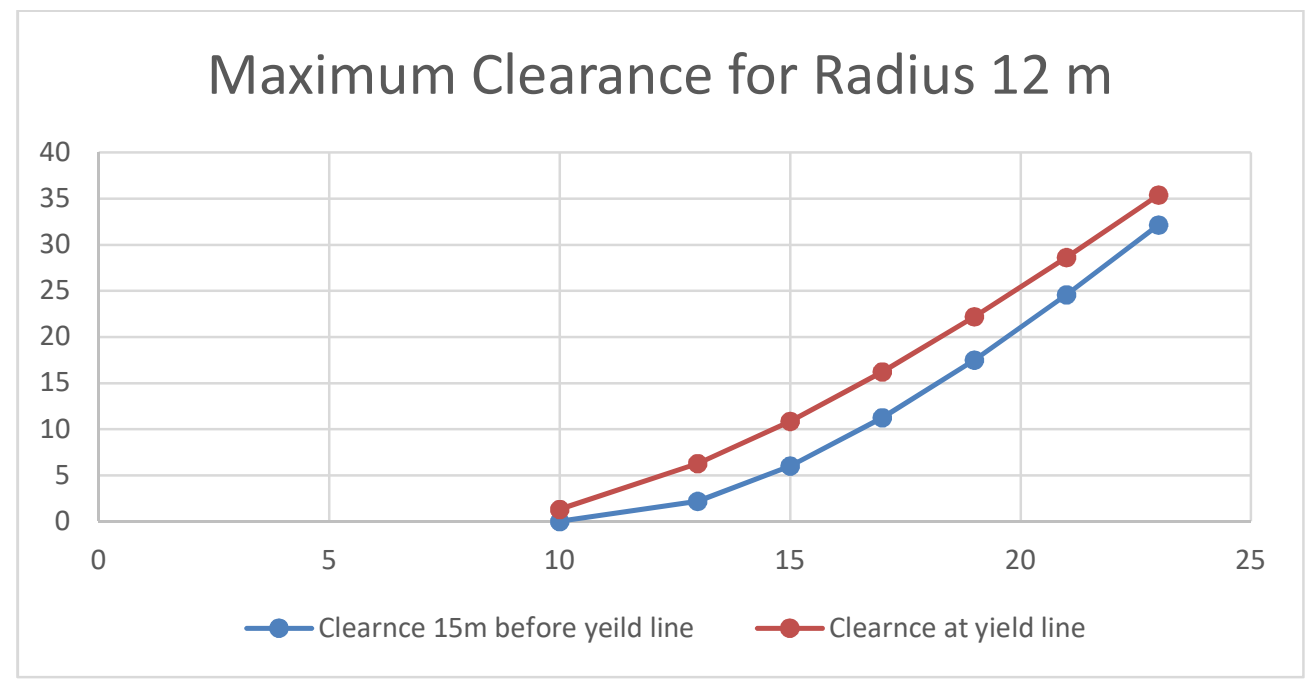

Figure 31:Graphical representation of clearance at different speeds for radius $12 \mathrm{~m}$

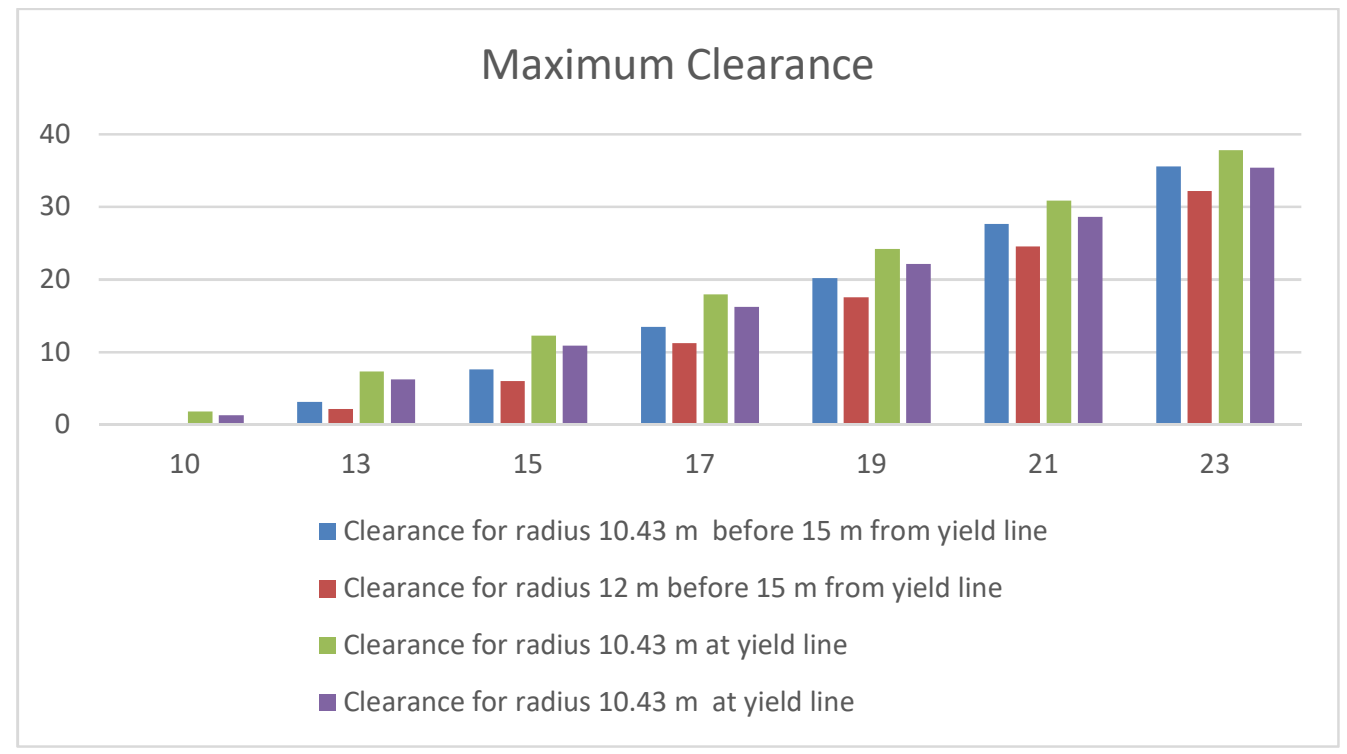

Figure 32: Bar chart depicting clearance value for all cases 


\subsection{Application Example}

Question -: Consider a multi-lane turbo roundabout with initial radius i.e. $\mathrm{R}_{1}=10.50 \mathrm{~m}$ or 34.45 feet, $\mathrm{V}_{\text {cir }}=16 \mathrm{mph}$, and $\mathrm{W}_{1}=10.46$ feet, and $\mathrm{W}_{\mathrm{c}}=16.9$ feet. The primary translation axis is at 15 degrees or 0.2618 radians with $y$ axis. The width of the median is $\mathrm{W}_{\mathrm{m}}=13.1234$ feet and $\mathrm{t}_{\text {critical }}=$ $5 \mathrm{sec}$. Determine the required maximum lateral clearance on the edge of truck apron for both the cases a) when vehicle is $15 \mathrm{~m}$ before yield line b) when vehicle is at yield line?

Solution-: For both the cases the input or given data is same is the same, table 7 shows all the given data.

Table 8: Given data for application example

\begin{tabular}{|c|c|c|}
\hline \multicolumn{3}{|c|}{ INPUT } \\
\hline Parameter & Value & units \\
\hline $\mathrm{X}_{\mathrm{O}}$ & 0 & feet \\
\hline $\mathrm{Y}_{\mathrm{O}}$ & 0 & feet \\
\hline $\mathrm{R}_{1}$ & 34.45 & feet \\
\hline $\mathrm{W}_{1}$ & 10.46 & feet \\
\hline $\mathrm{f}$ & 1.42 & feet \\
\hline $\mathrm{W}_{\mathrm{M}}$ & 13.12 & feet \\
\hline $\mathrm{W}_{\mathrm{C}}$ & 16.90 & feet \\
\hline $\mathrm{A}_{1}$ & 6.56 & feet \\
\hline $\mathrm{A}_{2}$ & 5.85 & feet \\
\hline $\mathrm{L}_{\mathrm{MIN}}$ & 49 & feet \\
\hline$\theta_{t}$ & 0.26 & radians \\
\hline $\mathrm{t}_{\mathrm{C}}$ & 5 & sec \\
\hline $\mathrm{V}_{\mathrm{C}}$ & 16 & mph \\
\hline $\mathrm{X}_{\mathrm{f}}$ & 42 & feet \\
\hline $\mathrm{Y}_{\mathrm{f}}$ & 26 & feet \\
\hline
\end{tabular}

Before finding all the significant coordinates of the points we first need to find all other radius of turbo roundabout. As mentioned in article $4.3\left(\mathrm{R}_{2}-\mathrm{R}_{1}=\left(\left(\mathrm{W}_{\mathrm{c}}+\mathrm{f}\right) / 2\right)\right.$ is used to find all other radius of turbo roundabout. It is an iterative process where after finding $R_{2}$, we can find $R_{3}$ using equation $\left(\mathrm{R}_{3}-\mathrm{R}_{2}\right)=\left(\left(\mathrm{W}_{\mathrm{c}}+\mathrm{f}\right) / 2\right)$ and similarly $\mathrm{R}_{4}$ and $\mathrm{R}_{5}$ can be found out. Table 8 shows the result of all other radius which are found using initial radius i.e. $\mathrm{R}_{1}$. 
Table 9: Output Radius of all other sides of translation axis

\begin{tabular}{|c|c|c|}
\hline \multicolumn{3}{|c|}{ OUTPUT RADIUS } \\
\hline Parameter & values & units \\
\hline$R_{2}$ & 43.61 & feet \\
\hline$R_{3}$ & 52.77 & feet \\
\hline$R_{4}$ & 61.93 & feet \\
\hline$R_{5}$ & 71.09 & feet \\
\hline
\end{tabular}

\section{Solution a) Case -1 (Vehicle at $15 \mathrm{~m}$ before yield line)}

For the vehicle $15 \mathrm{~m}$ or $49 \mathrm{ft}$ below yield line i.e. $\mathrm{L}_{\min }$ after finding all radius; first the centres of semicircles on both sides of translation axis is determined after which other coordinates of significant points are determined. Table 9 shows all the coordinates of the point and will also validate graphically through AutoCAD in further section.

Table 10: Coordinates of significant points for vehicle at $15 \mathrm{~m}$ before yield line

\begin{tabular}{|c|c|c|}
\hline $\begin{array}{l}\text { Coordinates of significant } \\
\text { points }\end{array}$ & X-Ordinate (in feet) & Y-Ordinate (in feet) \\
\hline Coordinates of new center & $X_{n}=2.18$ & $Y_{n}=8.16$ \\
\hline $\begin{array}{l}\text { Coordinates of approach } \\
\text { vehicle (Equation } 4 \text { and } 5 \text { ) }\end{array}$ & $X_{a}=-10.47$ & $Y_{a}=120.09$ \\
\hline $\begin{array}{l}\text { Coordinates of point " } \mathrm{e} " \\
\text { (Equation } 6 \text { and } 7 \text { ) }\end{array}$ & $X_{e}=-11.84$ & $Y_{e}=70.09$ \\
\hline $\begin{array}{l}\text { Coordinates of conflict point } \\
\text { (Equation } 11 \text { and } 12 \text { ) }\end{array}$ & $X_{c}=11.97$ & $Y_{c}=-65.35$ \\
\hline \multicolumn{3}{|c|}{ Total Distance travelled from conflict point $\left(0.278 * \mathrm{~V}_{\mathrm{c}}{ }^{*} \mathrm{t}_{\mathrm{c}}\right)=117.42 \mathrm{ft}$ or $35.79 \mathrm{~m}$} \\
\hline $\begin{array}{l}\text { Coordinates of circulating } \\
\text { conflicting vehicle } \\
\text { (Equation } 19 \text { and } 20)\end{array}$ & $X_{b}=44.13$ & $Y_{b}=-3.75$ \\
\hline $\begin{array}{c}\text { Clearance } \\
\text { (Equation 29) }\end{array}$ & \multicolumn{2}{|c|}{$\begin{array}{c}\text { (The value of which depends on } X_{g} \text { and } Y_{g} \text {, which further depend } \\
\text { on value of } X_{f} \text { and } Y_{f} \text { which are input values) }\end{array}$} \\
\hline
\end{tabular}

The following table shows the output numerical values received after inputting the given value in equations mentioned in chapter 4 . The table clearly depicts the equation number used in calculating that particular value. 


\section{Solution b) Case -2 (Vehicle is at yield line)}

For the second case we know that coordinate values of conflict point "c" and circulating vehicle point i.e. "b" remain constant. As shown in table 10 the values obtained for point "b", "c" and "e" are same as obtained in table 9 The value of point " $\mathrm{a}$ " changes due to which the slope of line $\mathrm{P}_{\mathrm{ab}}$ changes and ultimately the clearance value changes.

Table 11: Coordinates of significant values when vehicle is at yield line

\begin{tabular}{|c|c|c|}
\hline $\begin{array}{c}\text { Coordinates of significant } \\
\text { points }\end{array}$ & X-Ordinate (in feet) & Y-Ordinate (in feet) \\
\hline Coordinates of new centre & $\mathrm{X}_{\mathrm{n}}=2.18$ & $Y_{n}=8.16$ \\
\hline $\begin{array}{c}\text { Coordinates of approach } \\
\text { vehicle (Equation } 21 \text { and 22) }\end{array}$ & $X_{a}=-11.84$ & $Y_{a}=78.96$ \\
\hline $\begin{array}{l}\text { Coordinates of point "e" } \\
\text { (Equation } 6 \text { and 7) }\end{array}$ & $\mathrm{X}_{\mathrm{e}}=11.84$ & $\mathrm{Y}_{\mathrm{e}}=70.09$ \\
\hline $\begin{array}{l}\text { Coordinates of conflict point } \\
\text { (Equation } 11 \text { and 12) }\end{array}$ & $X_{c}=65.35$ & $Y_{c}=-11.97$ \\
\hline \multicolumn{3}{|c|}{ Total Distance travelled from conflict point $\left(0.278 * \mathrm{~V}_{\mathrm{c}} * \mathrm{t}_{\mathrm{c}}\right)=117.42 \mathrm{ft}$ or $35.79 \mathrm{~m}$} \\
\hline $\begin{array}{l}\text { Coordinates of circulating } \\
\text { conflicting vehicle } \\
\text { (Equation } 19 \text { and } 20)\end{array}$ & $\mathrm{X}_{\mathrm{b}}=44.13$ & $Y_{b}=-3.75$ \\
\hline $\begin{array}{c}\text { Clearance } \\
\text { (Equation 29) }\end{array}$ & \multicolumn{2}{|c|}{$\begin{array}{c}14.653 \\
\text { (The value of which depends on } \mathrm{X}_{\mathrm{g}} \text { and } \mathrm{Y}_{\mathrm{g}} \text {, which further } \\
\text { depend on value of } \mathrm{X}_{\mathrm{f}} \text { and } \mathrm{Y}_{\mathrm{f}} \text { which are input values) }\end{array}$} \\
\hline
\end{tabular}




\subsection{Validation of equations through AutoCAD}

For validating the analytical research work in preceding study, the input readings were plotted on AutoCAD and the results obtained has been shown in fig 33 below.

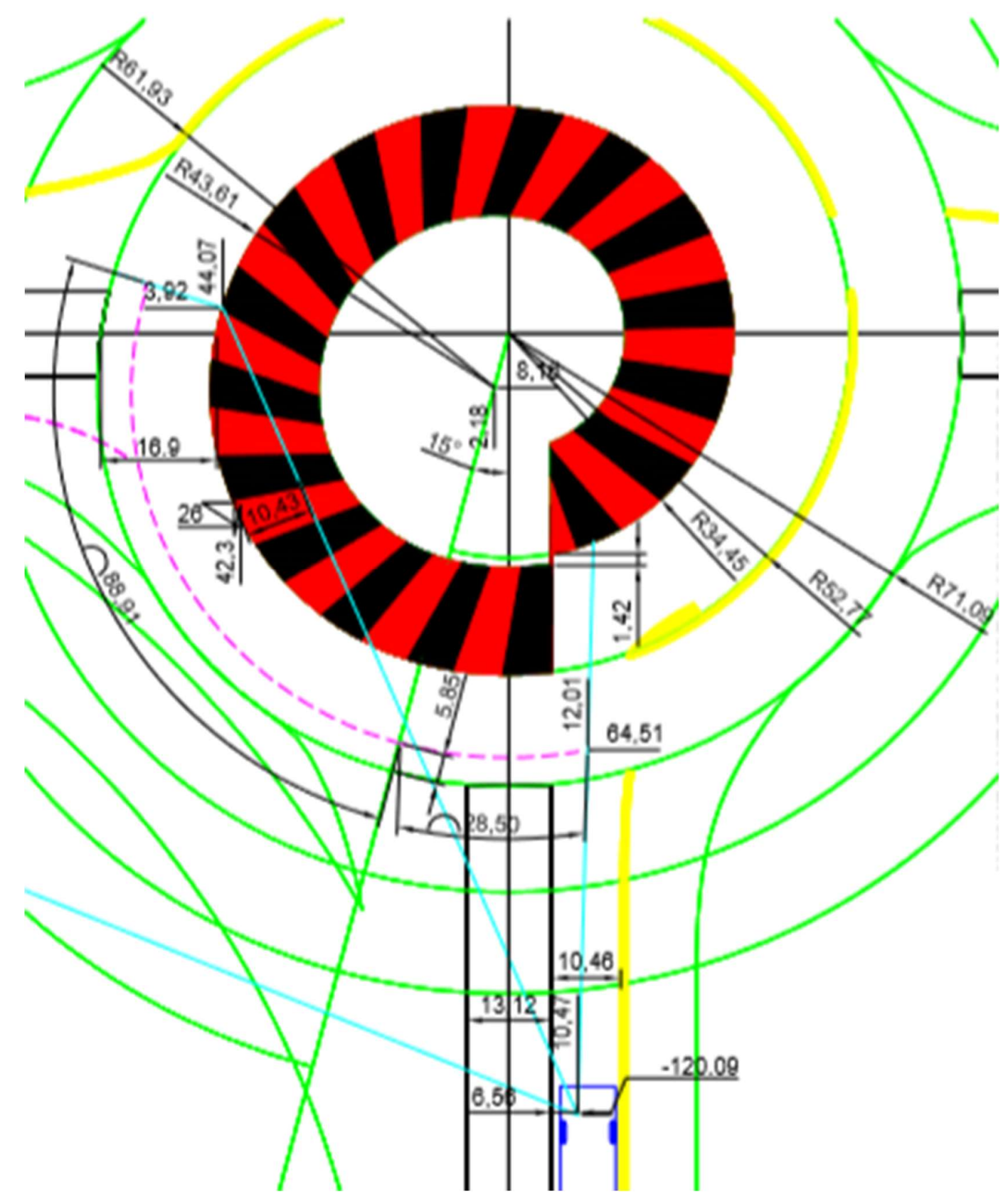

Figure 33: Validation of equations through AutoCAD 
The values obtained during graphical analysis were juxtaposed with results of variables calculated by means of mathematical equations in a tabular form as shown in Table 12 below-:

Table 12:Comparison of results of analytical \& Graphical Approach

\begin{tabular}{|c|c|c|c|c|c|}
\hline S.No & $\begin{array}{l}\text { Variables and } \\
\text { coordinates of Turbo } \\
\text { Roundabout }\end{array}$ & $\begin{array}{c}\text { Symbol } \\
\text { assigned } \\
\text { to } \\
\text { Variable }\end{array}$ & $\begin{array}{l}\text { Results as per } \\
\text { analytical } \\
\text { equation }\end{array}$ & $\begin{array}{l}\text { Results as per } \\
\text { graphical } \\
\text { analysis on } \\
\text { AutoCAD }\end{array}$ & Equations used \\
\hline 1 & Origin X-Coordinate & $\mathrm{X}_{0}$ & 0 & 0 & Input Data \\
\hline 2 & Origin Y-Coordinate & $\mathrm{Y}_{0}$ & 0 & 0 & Input Data \\
\hline 3 & Initial Radius & $\mathrm{R}_{1}$ & 34.45 feet & 34.45 feet & Input Data \\
\hline 4 & Second Radius & $\mathrm{R}_{2}$ & 43.61 feet & 43.61 feet & $\left.R_{2}-R_{1}=\left(\left(W_{c}+f\right) / 2\right)\right)$ \\
\hline 5 & Third Radius & $\mathrm{R}_{3}$ & 52.77 feet & 52.77 feet & $R_{3}-R_{2}=\left(\left(W_{c}+f\right) / 2\right)$ \\
\hline 6 & Fourth Radius & $\mathrm{R}_{4}$ & 61.93 feet & 61.93 feet & $R_{4}-R_{3}=\left(\left(W_{c}+f\right) / 2\right)$ \\
\hline 7 & Fifth Radius & $\mathrm{R}_{5}$ & 71.09 feet & 71.09 feet & $R_{5}-R_{4}=\left(\left(W_{c}+f\right) / 2\right)$ \\
\hline 8 & $\begin{array}{l}\text { Entering approach } \\
\text { width }\end{array}$ & $W_{1}$ & 10.46 feet & 10.46 feet & Input Data \\
\hline 9 & Shift & $f$ & 1.42 feet & 1.42 feet & Input Data \\
\hline 10 & $\begin{array}{c}\text { Circulatory roadway } \\
\text { width }\end{array}$ & $W_{C}$ & 16.90 feet & 16.9 feet & Input Data \\
\hline 11 & Median Width & $W_{M}$ & 13.12 feet & 13.12 feet & Input Data \\
\hline 12 & $\begin{array}{c}\text { Distance between the } \\
\text { driver's eye and edge } \\
\text { of median }\end{array}$ & $A_{1}$ & 6.56 feet & 6.56 feet & Input Data \\
\hline 13 & $\begin{array}{l}\text { Distance between the } \\
\text { driver's eye and outer } \\
\text { edge of circulatory } \\
\text { roadway width }\end{array}$ & $A_{2}$ & 5.85 feet & 5.85 feet & Input Data \\
\hline 14 & $\begin{array}{c}\text { Angle between } Y \text {-axis } \\
\text { and primary } \\
\text { translation axis }\end{array}$ & $\theta_{T}$ & $\begin{array}{l}0.26 \text { radians } \\
\text { Or } 15^{\circ}\end{array}$ & $15^{0}$ & Input Data \\
\hline 15 & $\begin{array}{l}\text { X-Coordinate of point } \\
\text { "f" }\end{array}$ & $X_{f}$ & 42 feet & -42 feet & Input Data \\
\hline 16 & $\begin{array}{c}\text { Y-Coordinate point } \\
\text { "f" }\end{array}$ & $Y_{f}$ & 26 feet & -26 feet & Input Data \\
\hline 17 & $\begin{array}{l}\text { X-Coordinate new } \\
\text { center }\end{array}$ & $X_{n}$ & 2.18 feet & -2.18 feet & $x_{n}=\frac{W_{c}}{2} \operatorname{Sin} \theta_{T}$ \\
\hline 18 & $\begin{array}{l}\text { Y-Coordinate new } \\
\text { center }\end{array}$ & $Y_{n}$ & 8.16 feet & -8.16 feet & $y_{n}=\frac{W_{c}}{2} \operatorname{Cos} \theta_{T}$ \\
\hline
\end{tabular}




\begin{tabular}{|c|c|c|c|c|c|}
\hline 19 & $\begin{array}{l}\text { X-Coordinate of } \\
\text { approach vehicle }\end{array}$ & $X_{a}$ & -10.47 feet & 10.47 feet & $x_{a}=\frac{W_{m}}{2}+W_{1}-A_{1}$ \\
\hline 20 & $\begin{array}{l}\text { Y-Coordinate of } \\
\text { approach vehicle }\end{array}$ & $Y_{a}$ & 120.09 feet & -120.09 feet & $y_{a}=R_{5}+L_{\min }$ \\
\hline 21 & $\begin{array}{l}\text { X-Coordinate of } \\
\text { conflict point }\end{array}$ & $X_{C}$ & -11.97 feet & 12.01 feet & $x_{c}=\left\{\left(R_{5}-A_{2}\right)^{2}-y_{c}^{2}\right\}^{0.5}$ \\
\hline 22 & $\begin{array}{l}\text { Y-Coordinate of } \\
\text { conflict point }\end{array}$ & $\mathrm{Y}_{\mathrm{C}}$ & 65.35 feet & - 64.51 feet & $y_{c}=\frac{-b \pm \sqrt{b^{2}-4 a c}}{2 a}$ \\
\hline 23 & $\begin{array}{l}\text { X-Coordinate of } \\
\text { circulating conflicting } \\
\text { vehicle }\end{array}$ & $X_{b}$ & 44.13 feet & -44.07 feet & $\begin{array}{r}x_{b}=\left(R_{2}\right) \cos \theta_{b} \\
+\frac{W_{c}}{2} \sin \theta_{T}\end{array}$ \\
\hline 24 & $\begin{array}{l}\text { Y-Coordinate of } \\
\text { circulating conflicting } \\
\text { vehicle }\end{array}$ & $Y_{b}$ & -3.75 feet & 3.92 feet & $\begin{array}{r}y_{b}=-\left(R_{2}\right) \sin \theta_{b} \\
+\frac{W_{c}}{2} \cos \theta_{T}\end{array}$ \\
\hline 25 & $\begin{array}{l}\text { Distance covered by } \\
\text { vehicle between } \\
\text { point 'c' and ' } z \text { '. }\end{array}$ & $\mathrm{d}_{3}$ & 11.43 feet & & $d_{3}=\theta_{3} \times\left(R_{5}-A_{2}\right)$ \\
\hline 26 & $\begin{array}{l}\text { Distance covered } \\
\text { along arc subtended } \\
\text { by the angle } \theta_{T}\end{array}$ & $d_{2}$ & 17.07 feet & 28.50 feet & $d_{2}=\theta_{T} \times\left(R_{5}-A_{2}\right)$ \\
\hline 27 & $\begin{array}{l}\text { Rest of the distance } \\
\text { which can be found } \\
\text { out by subtracting } \\
\text { ' }\left(\mathrm{d}_{1}+\mathrm{d}_{2}\right) \text { ' from total } \\
\text { distance 'd'. }\end{array}$ & $d_{1}$ & 88.91 feet & 88.91 feet & $\begin{array}{c}d=0.278 V_{c} \mathrm{t}_{\mathrm{c}} \\
d_{1}=d-\left(d_{2}+d_{3}\right)\end{array}$ \\
\hline 28 & $\begin{array}{l}\text { Lateral Clearance at } \\
\text { point "f" }\end{array}$ & $C_{f}$ & 10.029 & 10.43 & $\begin{array}{l}\mathrm{C}_{\mathrm{f}}=\left(R_{2}\right)- \\
\sqrt{\left(x_{g}-x_{n}\right)^{2}+\left(y_{g}-y_{n}\right)^{2}}\end{array}$ \\
\hline
\end{tabular}

It was observed from the above comparison table 12 that the values obtained in table 10 which were derived using analytical equations in chapter 4 approximately matches with the coordinates values of obtained by graphical approach in fig 33. Thus, graphical results obtained validate results deduced by analytical method. Moreover, on closely observing table 12 we can see that the input values are exactly same in analytical and graphical method which is understandable, but the exact same value of all other radius, coordinates of approach vehicle, coordinates of new centre and distances $\mathrm{d} 1, \mathrm{~d} 2, \mathrm{~d} 3$ are due to the simple mathematical equations used which are described in the above table. The simple addition, subtraction and trigonometry explains why it gives us the same value. However, a little variation is observed in variable coordinates of conflict point and 
coordinates of circulating conflicting vehicle and clearance all of which uses a little complex mathematics. In case of coordinates of circulating conflict vehicles, we use complex quadratic equations for which the values of "a", "b" and "c" further depend on number of other parameters, in case of clearance and coordinates of circulating conflict vehicles the equations uses variables which further depend on number of other parameters; all of these reasons explains the variation observed in these 3 cases. Although there is difference in the coordinate sign value of the fig 33 and table 10, but the sign of coordinate values of table 10 are justified by assumption 4 in article 4.2. Hence our analytical equations are true and validated. 


\subsection{Conclusion}

The conflict points and thus crash frequency increases when modern roundabouts functions on multi-lanes in comparison to their working on single lanes. Comparative studies suggested that the Turbo roundabouts are the most viable solution for increased safety and efficiency on these multilane intersections. Studies also show that barring a few situations capacity at turbo roundabouts significantly increased by nearly one third. The different shapes of turbo roundabouts can be decided catering to different quantum, pattern and movement of traffic. Various geometric features have to be provided with turbo roundabouts, but guidelines published in different countries are not in consensus with their dimensions and provision. These geometric elements are greatly influenced by or influences sight distances. In the study Intersection sight distance was analytically calculated and established using sight lines and sight triangles which help the drivers of conflicting vehicles to see the approaching vehicles. Graphical method though in great use was cumbersome so ready

to use equations were derived, verified and established using practical application. It was concluded during research that-:

- Double lane roundabout has more crashes when compared to the single lane roundabout. The difference is in property damage clashes rather than injury collisions.

- Crashes at multi-lane roundabouts are reduced drastically when turbo roundabouts are constructed.

- Capacity at turbo roundabouts are believed to be more but more research and study must be done to validate these facts.

- In terms of capacity turbo roundabouts are effective in case of heavy vehicle flow as long as capacity of the intersection is analysed using the right passenger equivalent factor i.e. $\mathrm{E}_{\mathrm{T}}$ which is different for different percentage of heavy vehicles and different entry instead of a single value as suggested by HCM.

- Long combination vehicles can manoeuvre safely if the geometric feature of raised mountable divider and truck apron is provided at turbo roundabout intersection. These features help the vehicles to manoeuvre by accommodating their extra turning space. This concept is especially useful in urban areas where there is high percentage of articulated 
buses i.e. A-BUS are there. These buses also use truck apron and raised mountable divider to turn in case of scarcity of space.

- Turbo blocks are established as a foundation of the turbo roundabout, where circular arcs are drawn whose radius changes every time after primary translation axis.

- Intersection sight distance is established to increase the safety perspective, but if the designer provides more than intersection sight distance it may increase crash rate. Landscaping techniques can be used to restrict sight lines.

- Equations which were developed analytically are in general form and are ready-to-use tools for calculation of sight distances and clearances. They were also validated through a practical application. 


\section{Bibliography}

AASHTO, (2001). A Policy on Geometric Design of Highway and Streets

Austroads (2009), Guide to road design: Part 4A: unsignalized and signalized intersections, Austroads, Sydney, NSW

Bailey, S. (2016, October 13). Roundabouts are 'just another piece of the road' becoming popular in Canada.

Džambas, T., Ahac, S., \& Dragčević, V. (2017). Geometric design of turbo roundabout Tehnicki Vjesnik - Technical Gazette, 24(1), 309-318.

D. Turner, "Roundabouts: A Literature Review," Daniel Turner, 2011.

E. Hauer, Observational Before-After Studies in Road Safety, Toronto: Elsevier Science Ltd., 1997.

Easa, S.M. (2017). Lateral clearance needs for stopping sight distance at symmetrical single-lane roundabouts. Proc., Transportation Research Board Conference, Washington, D.C.

Easa, S.M. (2016). DESIGN GUIDELINES FOR SYMMETRICAL SINGLELANE ROUNDABOUTS BASED ON INTERSECTION SIGHT DISTANCE., Journal of Transportation Research Board, Washington, D.C.

Fortuijn, Lambertus G H. 2009. Turbo Roundabouts Estimation of Capacity.(2130): 83-92.

Gaspar, M. (2013, May). Turbo-roundabout use and design, 6th annual conference on planning and research.

Giuffre Orazio., Grana Anna,(April 2016) Passenger car equivalent for heavy vehicles crossing turbo-roundabouts

Grana Anna,(2012) Comparing Performances opf Turbo-roundabouts and Double lane Roundabouts". 
Gazzarri, A., Pratelli, A., Souleyrette, R. R., \& Russell, E. R. (n.d.). Unconventional roundabout geometries for large vehicles or space constraints.

J.C. Engelsman and M. Uken. (n.d.). TURBO ROUNDBOUT AS AN ALTERNATIVE TO TWO LANE ROUNDABOUTS.

L. G. Fortuijin, Turbo Roundabouts: Design Principles and Safety Performance, Transportation Research Record, vol. 2096, pp. 16-24, 2009.

Livingston, S. C. (2014). DESIGN VEHICLE INFLUNCE TO GEOMETRIC DESIGN OF TURBO-ROUNDABOUTS. Transsoft Solutions.

Murphy, T., \& Manager, S. P. (2015). THE TURBO ROUNDABOUT A FIRST IN NORTH AMERICA, for the conference of the Transportation Association of Canada.

MDOT. 2007. "Michigan Department of Transportation.” (November).

NCHRP. (n.d.). Roundabout an Informational Guide, Federal Highway Administration, Publication No. FHWA-RD-00-067.

Pumphrey, C. (2018, March 08). How Roundabouts Work

Silva, Ana Bastos, Luís Vasconcelos, and Sílvia Santos. 2014. Moving from Conventional Roundabouts to Turbo-Roundabouts. Procedia - Social and Behavioral Sciences

Serbian Authority for Roads, Beograd, 2012).

TRB, Transportation Research Board. (2010). Roundabouts: An informational guide. NCHRP Rep. 672, Washington, DC.

Tollazzi, T., \& Engineering, C. (2014). Modern types of roundabouts - trends and future expectations.

Tollazi, T.; Renčelj, M. Modern and alternativAkçelik, Rahmi. 2005. Capacity and Performance Analysis of Roundabout Metering Signals.” TRB National Roundabout Conference (May)

USDOT. (2017). Chapter 6, Simple roundabout geometric Design, United States Department of Transportation.

Washington State Department of Transportation. (2017, July). Chapter 13 - Roundabouts Design Manual M 22-01.

Walkability Audit Shows Promise for City. (2014, December 29).

Weber, P., \& P.Eng, (2007). Chapter 5 of the Synthesis of North American Roundabout Practice, Presented at Road Safety Geometric Design Session of 2007. 
